\title{
REACTIVATION OF AN IDLE LEASE TO INCREASE HEAVY OIL RECOVERY THROUGH APPLICATION OF CONVENTIONAL STEAM DRIVE TECHNOLOGY IN A LOW DIP SLOPE AND BASIN RESERVOIR IN THE MIDWAY-SUNSET FIELD, SAN JAOQUIN BASIN, CALIFORNIA
}

DOE Class III Oil Technology Demonstration

Cooperative Agreement No.: DE-FC22-95BC14937--08

Contractor Name and Address: Energy \& Geoscience Institute at the University of Utah, 423 Wakara Way, Salt Lake City, UT 84108

Date of Report: October 21, 1997

Award Date: June 14, 1995

Anticipated Completion Date: March 13, 2000

Principal Investigator: Steven Schamel

Project Manager: Jerry Castille, Bartlesville Project Office

Reporting Period: June 13, 1995-June 13, 1996 


\section{Disclaimer}

This report was prepared as an account of work sponsored by an agency of the United States Government. Neither the United States Government nor any agency thereof, nor any of their employees, makes any warranty, express or implied, or assumes any legal liability or responsibility for the accuracy, completeness, or usefulness of any information, apparatus, product, or process disclosed, or represents that its use would not infringe privately owned rights. Reference herein to any specific commercial product, process, or service by trade

name, trademark, manufacturer, or otherwise does not necessarily constitute or imply its endorsement, recommendation, or favoring by the United States Government or any agency thereof. The views and opinions of authors expressed herein do not necessarily state or reflect those of the United States Government or any agency thereof. 


\section{REACTIVATION OF AN IDLE LEASE TO INCREASE HEAVY OIL RECOVERY THROUGH APPLICATION OF CONVENTIONAL STEAM DRIVE TECHNOLOGY IN A LOW DIP SLOPE AND BASIN RESERVOIR IN THE MIDWAY-SUNSET FIELD, SAN JAOQUIN BASIN, CALIFORNIA}

DOE Class III Oil Technology Demonstration

Cooperative Agreement No.: DE-FC22-95BC14937

\section{Annual Report}

June 1995 to June 1996

Edited and assembled by Steven Schamel

Energy \& Geoscience Institute at the University of Utah

Report Contributors

Milind Deo

Creties Jenkins

Doug Sprinkel

Robert Swain

Ray Wydrinski 


\section{Table of Contents}

Executive Summary $\quad 4$

$\begin{array}{ll}\text { 1. Introduction } & 9\end{array}$

Objective

Project organization

Project activities in Year 1

Tasks remaining in Budget Period 1

2. Core Description and Petrophysical Analysis of Pru 101

Introduction

Visual core description

Analysis of routine core measurements

Analysis of X-ray diffraction data

Analysis of thin-sections

Petrophysical analysis

Water saturation and well performance

Sand and barrier continuity

Conclusions

3. Stratigraphic Model

Introduction

Stratigraphic analysis

4. Reservoir Simulation

Introduction

Two-dimensional Simulations

Dip and bottomwater study

Effect of lower permeability surfaces

5. Activities at the Pru Demonstration Site

Introduction

Cyclic steaming baseline tests

Conclusion

6. Technology Transfer

References Cited 


\begin{abstract}
REACTIVATION OF AN IDLE LEASE TO INCREASE HEAVY OIL RECOVERY THROUGH APPLICATION OF CONVENTIONAL STEAM DRIVE TECHNOLOGY IN A LOW DIP SLOPE AND BASIN RESERVOIR IN THE MIDWAY-SUNSET FIELD, SAN JAOQUIN BASIN, CALIFORNIA
\end{abstract}

Cooperative Agreement No.: DE-FC22-95BC14937

This project reactivates ARCO's idle Pru Fee lease in the Midway-Sunset field, California and conducts a continuous steamflood enhanced oil recovery demonstration aided by an integration of modern reservoir characterization and simulation methods. Cyclic steaming is being used to reestablish baseline production within the reservoir characterization phase of the project. During the demonstration phase scheduled to begin in January 1997, a continuous steamflood enhanced oil recovery will be initiated to test the incremental value of this method as an alternative to cyclic steaming. Other economically marginal Class III reservoirs having similar producibility problems will benefit from insight gained in this project. The objectives of the project are: (1) to return the shut-in portion of the reservoir to optimal commercial production; (2) to accurately describe the reservoir and recovery process; and (3) to convey the details of this activity to the domestic petroleum industry, especially to other producers in California, through an aggressive technology transfer program. 


\title{
Executive Summary
}

\section{REACTIVATION OF AN IDLE LEASE TO INCREASE HEAVY OIL RECOVERY THROUGH APPLICATION OF CONVENTIONAL STEAM DRIVE TECHNOLOGY IN A LOW DIP SLOPE AND BASIN RESERVOIR IN THE MIDWAY-SUNSET FIELD, SAN JAOQUIN BASIN, CALIFORNIA}

\author{
Cooperative Agreement No.: DE-FC22-95BC14937
}

This project reactivates ARCO's idle Pru Fee lease in the Midway-Sunset field, California and conducts a continuous steamflood enhanced oil recovery demonstration aided by an integration of modern reservoir characterization and simulation methods. Cyclic steaming is being used to reestablish baseline production within the reservoir characterization phase of the project. During the demonstration phase scheduled to begin in January 1997, a continuous steamflood enhanced oil recovery will be initiated to test the incremental value of this method as an alternative to cyclic steaming. Other economically marginal Class III reservoirs having similar producibility problems will benefit from insight gained in this project. The objectives of the project are: (1) to return the shut-in portion of the reservoir to optimal commercial production; (2) to accurately describe the reservoir and recovery process; and (3) to convey the details of this activity to the domestic petroleum industry, especially to other producers in California, through an aggressive technology transfer program.

The 40 ac Pru Fee property is located in the super-giant Midway-Sunset field and produces from the late Miocene Monarch Sand, part of the Monterey Formation. The Midway-Sunset Field was drilled prior to 1890. In 1991 cumulative production from the field reached two billion barrels, with remaining reserves estimated to exceed $695 \mathrm{MMBO}$. In the Pru Fee property, now held by ARCO Western Energy, cyclic steaming was used to produce $13^{\circ} \mathrm{API}$ oil. However, the previous operator was unable to develop profitably this marginal portion of the Midway-Sunset field using standard enhanced oil recovery technologies and chose rather to leave more than 3.0 MMBO of oil in the ground that otherwise might have been produced from the 40 ac property. Only 927 MBO had been produced from the property when it was shut-in in 1987. This is less than $15 \%$ of the original oil-in-place, which is insignificant compared to typical heavy oil recoveries in the Midway-Sunset field of 40 to $70 \%$. Target additional recoverable oil reserves from the 40 ac property are $2.9 \mathrm{MMBO}$ or greater. The objective of the demonstration project is to encourage a similar incremental increase in production in all other marginal properties in the Midway-Sunset and adjacent fields in the southern San Jaoquin Basin.

A previously idle portion of the Midway-Sunset field, the ARCO Western Energy Pru Fee property, is being brought back into commercial production through tight integration of geologic characterization, geostatistical modeling, reservoir simulation, and petroleum 
engineering. This property, shut-in over a decade ago as economically marginal using conventional cyclic steaming methods, has a 200-300 foot thick oil column in the Monarch Sand. However, the sand lacks effective steam barriers and has a thick water-saturation zone above the oil-water contact. These factors require an innovative approach to steam flood production design that will balance optimal total oil production against economically viable steam-oil ratios and production rates. The methods used in the Class III demonstration are accessible to most operators in the Midway-Sunset field and could be used to revitalize declining production of heavy oils throughout the region.

\section{Cyclic Steaming Baseline Tests}

One of the main objectives of Budget Period 1 was to return the Pru Fee property to economic production and establish a baseline productivity with cyclic steaming. By the end of June 1996, all Pru producers except well 101 had been cyclic steamed two times. Each steam cycle was around 10,000 barrels of steam (BS) per well. No mechanical problems were found in the existing old wellbores. After the first round of steam cycles it was readily apparent that the new Pru 101 well was producing much better than the old existing Pru wells. In fact two of the old producers had no response at all to the first steam cycle. There were several possible explanations for the difference in performance, including (1) error in steam measurement/allocation, (2) misplacement of steam in the reservoir and (3) formation damage in the older wells.

Total Pru Fee production following the first steam cycle was about 70 BOPD and 300 BWPD, as shown on the attached lease production plot (Figure 4). Due to the concerns about steam placement and measurement, the second round of steam cycles were started before production had stabilized from the first cycle. The drop in production during the second cycle is primarily due to producers being taken off line to inject the second steam cycle.

The total lease production resulting from the first steam cycle was lower than expected. As mentioned previously this is due to poor performance in the old existing wells. Post steam oil rates in the older wells were less than 10 BOPD, as compared to the post steam oil rate in new Pru 101 well of 30 BOPD. However, early production results following the second steam cycle are encouraging. Some wells are responding better to the second steam cycle. Time will tell whether this trend will continue. If it does, this may indicate that although the old wells may have a high near wellbore skin as compared to a new well, they may still have the potential to be economic producers as the reservoir heats up with continued injection.

After several years of being shut-in, the existing producers on the Pru property are in reasonable mechanical condition, and can therefore be utilized as viable producers in whatever development plan we determine is optimum. Production response to cyclic steam is very encouraging in the new producer, however productivity in the old producers appears to be limited in comparison. Effectively heating the entire reservoir will be the key challenge in the economically developing the Pru property. 


\section{Geological and reservoir characterization}

The designated project area, the 40 ac Pru Fee property and a corridor $500 \mathrm{ft}$ in width surrounding the property, contains 143 wells of various ages. Slightly more than 100 of the wells have geophysical log suites available. In the first quarter of the project, those log suites not already in the possession of ARCO Western Energy were assembled. Where only paper logs were available, the logs were digitized. During the present quarter, the remaining suites of paper logs available from diverse sources were digitized and added to the project TerraStation ${ }^{\mathrm{TM}}$ database. In addition, during this quarter the core pulled from the new injection well on the site, Pru 101, was analyzed and made available for inspection by the project team. The examination of the core included:

- Visual core description of lithology, bedding character and oil staining,

- Routine analyses by Core Laboratories of 246 samples of porosity, permeability and fluid saturations,

- Thin section analysis of 33 samples, of which 17 were submitted for x-ray diffraction (XRD) analysis,

- Sieve and laser particle-size analysis conducted on 10 sand samples of a range of visual textures, and

- A log analysis model of the Monarch Sandstone using PETCOM software to calculate effective porosity, water saturation, non-reservoir volume and permeability.

The Pru 101 well, located near the center of the Pru Fee property, entered the top of the Monarch Sandstone at a depth of $1100 \mathrm{ft}$, passed through $268 \mathrm{ft}$ of dominantly medium and coarse-grained, oil-stained sand to penetrate the oil-water contact at $1368 \mathrm{ft}$ depth. The base of the Monarch Sandstone was not reached in the well. About $96 \%$ of the core recovered from the Monarch Sandstone is highly porous oil-stained sand. The remaining $4 \%$ of the core is non-reservoir diatomaceous mudstone and fine sand.

The cored interval through the Monarch Sand consists of major fining-upward sequences. A typical sequence begins with a pebble or granule sand that progresses upward through coarse grained sand, medium sand, and perhaps interbedded bioturbated or muddy sand before passing abruptly into another pebble or granule sand that begins the next sequence. Overall, however, the full section from the oil-water contact to the top of the Monarch (1106.4 to1368.6 ft.) coarsens upward, which is consistant with a prograding shoreline and progressive filling of the basin. The proposed depositional model is a steepfaced fan-delta prograding onto a shallow marine shelf. Periodic remodilization of fandelta deposits as debris flows generate slumps and turbidity currents that deposit the Monarch Sand. The muddy fine sands capping many of the turbidites are deposited from suspension as the flow wanes. The absence of any true marine clays indicates short periods between successive debris flows and turbidites.

A provisional stratigraphic framework was established aided by the core description, lithologic analyses, and geophysical logs from the Pru 101 well. Five potentially correlatable stratigraphic markers were identified with this well. These markers are relatively thin (2-10 ft) intervals of fine sand and diatomaceous mudstone that separate thick (30-46 ft) sandstone units. The sand packets each have distinctly different character 
defined by the style of bedding and/or relative abundance of matrix-supported pebble and boulder beds. The fragments are dominantly subrounded clasts of granite, gneiss and diatomaceous mudstone.

The five stratigraphic markers, the top of the Monarch Sandstone and the oil-water contact have been correlated in well logs across the study area. Using TerraStation ${ }^{\mathrm{TM}}$, these surfaces have been mapped in a set of seven structure contour maps that serve as the provisional stratigraphic model for the Monarch reservoir at the demonstration site. This stratigraphic model is now being refined using geostatistical methods.

\section{Reservoir simulation}

The stratigraphic reservoir characterization revealed that the reservoir between top of the Monarch to the oil-water contact consists of six high-permeability oil-bearing zones separated by thin zones of relatively lower permeability. The effect of the thicknesses and permeabilities of the separating surfaces on oil production was examined using a series of thermal simulations. All the simulations were performed using STARS, a thermal reservoir simulator developed by Computer Modeling Group, Calgary, Canada.

The thickness, permeability sensitivity studies were performed using a two-dimensional model that represented the stacked nature of the reservoir. One other objective of these investigations was to study response to three different types of thermal treatments; the conventional cyclic steam process, the conventional steamflood and a combination of cyclic steam and the steamflood processes. The combination process was explored since it is a general practice in the field to stimulate oil producers in steamflood processes.

The effect of the permeability of the surfaces on the cyclic process was investigated. Production is found to be not very sensitive to the interbedded surface permeability unless the surface permeability was less than $10 \mathrm{md}$., compared to a permeability on the order of $3000 \mathrm{md}$ for the oil bearing zones. Thickness of the "barrier" has even less of an impact on oil production by steam processes.

For identical set of reservoir characteristics, cumulative production from the conventional steam-flood and the combination cyclic-flood was essentially equal (about $47 \%$ of the original oil in place for a 3 -year project). The cumulative recovery from the conventional cyclic process was about $42 \%$ of the oil in place after 10 years of operation. The steam-oil ratios for the cyclic (10-year), the steam-flood (3-year) and the combination processes were 16, 18 and 13 respectively. Thus, from an operational stand-point, the cyclic-flood combination appeared to be the best option. These conclusions will have to be validated using more realistic reservoir representations.

In addition to completion and dip evaluations, a 11-layer two-dimensional model with eight wells (four injectors, four producers) was used to perform additional sensitivity studies. Preliminary geologic analysis of the reservoir had revealed that the pay zone consisted of thick uniform layers separated by thin lower permeability layers. The production response was evaluated as the permeability contrast between the high and the 
low permeability zones and the thickness of the lower permeability layers were varied. Once again, the three different processes were studied. Comprehensive results of the 2-D sensitivity studies will be presented in the Budget Period I report.

\section{Technology transfer}

A poster presentation summarizing the initial progress made on this project, Integrated, multidisciplinary reservoir characterization, modeling and engineering leading to enhanced oil recovery from the Midway-Sunset field, California, was presented at the 1996 Annual AAPG meeting in San Diego in May 1996. The paper was an invited contribution to the session on "Application of New Technologies to Enhance Oil Recovery”. 


\section{Chapter 1}

\section{Introduction}

\section{Objective}

This project reactivates ARCO's idle Pru Fee lease in the Midway-Sunset field, California and conducts a continuous steamflood enhanced oil recovery demonstration aided by an integration of modern reservoir characterization and simulation methods. Cyclic steaming is being used to reestablish baseline production within the reservoir characterization phase of the project. During the demonstration phase scheduled to begin in January 1997, a continuous steamflood enhanced oil recovery will be initiated to test the incremental value of this method as an alternative to cyclic steaming. Other economically marginal Class III reservoirs having similar producibility problems will benefit from insight gained in this project. The objectives of the project are: (1) to return the shut-in portion of the reservoir to optimal commercial production; (2) to accurately describe the reservoir and recovery process; and (3) to convey the details of this activity to the domestic petroleum industry, especially to other producers in California, through an aggressive technology transfer program.

The 40 ac Pru Fee property is located in the super-giant Midway-Sunset field (Figure 1) and produces from the late Miocene Monarch Sand, part of the Monterey Formation. The Midway-Sunset Field was drilled prior to 1890. In 1991 cumulative production from the field reached two billion barrels, with remaining reserves estimated to exceed 695 MMBO. In the Pru Fee property, now held by ARCO Western Energy, cyclic steaming was used to produce $13^{\circ}$ API oil. However, the previous operator was unable to develop profitably this marginal portion of the Midway-Sunset field using standard enhanced oil recovery technologies and chose rather to leave more than 3.0 MMBO of oil in the ground that otherwise might have been produced from the 40 ac property. Only $927 \mathrm{MBO}$ had been produced from the property when it was shut-in in 1987. This is less than $15 \%$ of the original oil-in-place, which is insignificant compared to typical heavy oil recoveries in the Midway-Sunset field of 40 to $70 \%$. Target additional recoverable oil reserves from the 40 ac property are $2.9 \mathrm{MMBO}$ or greater. The objective of the demonstration project is to encourage a similar incremental increase in production in all other marginal properties in the Midway-Sunset and adjacent fields in the southern San Jaoquin Basin.

A previously idle portion of the Midway-Sunset field, the ARCO Western Energy Pru Fee property, is being brought back into commercial production through tight integration of geologic characterization, geostatistical modeling, reservoir simulation, and petroleum engineering. This property, shut-in over a decade ago as economically marginal using conventional cyclic steaming methods, has a 200-300 foot thick oil column in the Monarch Sand. However, the sand lacks effective steam barriers and has a thick water-saturation zone above the oil-water contact. These factors require an innovative approach to steam flood production design that will balance optimal total oil production against economically viable steam-oil ratios and production rates. The methods used in the Class III 


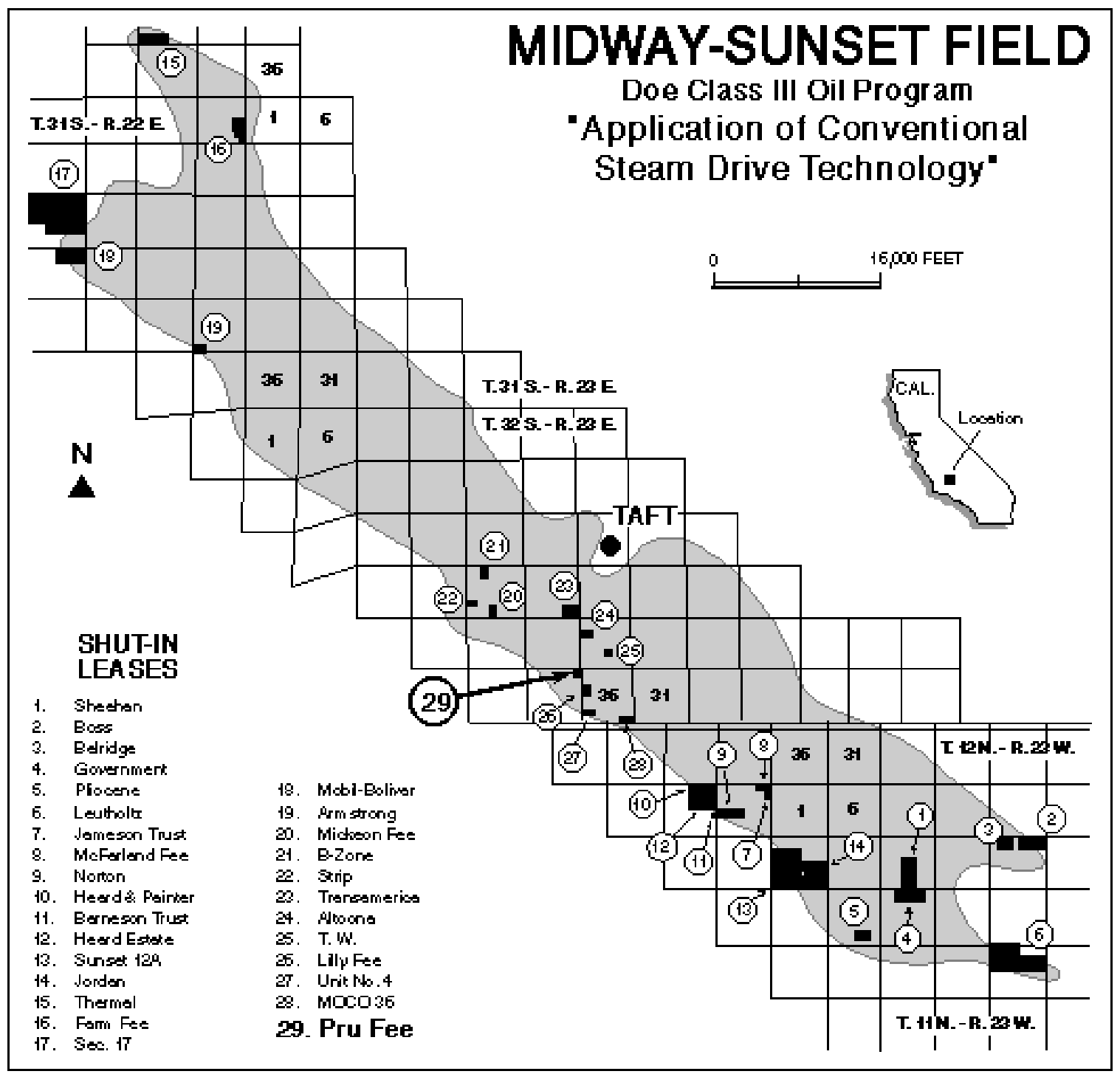

Figure 1.1: Index map of the Midway-Sunset field showing location of the Pru Fee property and other shut-in leases.

demonstration are accessible to most operators in the Midway-Sunset field and could be used to revitalize declining production of heavy oils throughout the region.

\section{Project Organization}

This Class III Oil Technology Demonstration, which is sponsored with matching funds from the U.S. Department of Energy, Office of Fossil Fuels, involves the collaboration of three separate organizations:

- the University of Utah, represented by the Energy \& Geoscience Institute, serving as the Prime Contractor and project coordinator

- ARCO Western Energy, the owner and operator of the Pru Fee property

- the Utah Geological Survey, responsible for technology transfer and geologic evaluation. 
The project team members and their particular areas of responsibility to the project are:

Energy \& Geoscience Institute at the University of Utah (Salt Lake City, UT)

- Dr. Steven Schamel - project manager and coordinator

- Dr. Craig Forster - reservoir characterization and geostatistics

Department of Chemical and Fuels Engineering, University of Utah

- Dr. Milind Deo - reservoir characterization and simulation

- Ms. Hongmei Huang - reservoir simulation

ARCO Western Energy (Bakersfield, CA)

- Mr. Robert Swain - petroleum engineering and site management

- Mr. Mike Simmons - petroleum geology and reservoir characterization

ARCO Exploration and Production Technology (Plano, TX)

- Dr. Creties Jenkins - reservoir characterization and core description

- Dr. Ray Wydrinski - petrophysics and log analysis

Utah Geological Survey (Salt Lake City, UT)

- Dr. Doug Sprinkel - stratigraphic analysis and reservoir characterization

- Dr. Roger Bon - technology transfer

Authors of this annual report are: Creties Jenkins and Ray Wydrinski (Chapter 2), Doug Sprinkel (Chapter 3), Milind Deo (Chapter 4), Robert Swain (Chapter 5). The report was edited and assembled by Steven Schamel.

\section{Project Activities in Year 1}

A variety of activities have been carried out during the period July 1995 through June 1996 leading to completion of the program for Budget Period 1, which concludes in December 1996.

Install lease production facilities and return wells to production

In preparation for the cyclic injection and production baseline tests at the demonstration site, the site has been resurveyed, the PLC panel has been upgraded with new dynamic surveillance software, many of the flowlines have been replaced, the production header has been repaired and modified, and a nearby idle fresh water knockout (FWKO) has been converted to the Pru wet lact. Work has begun to convert the old Pru wet lact to a well tester. Idle wells already on the Pru demonstration site have been inspected, repaired and equipped as injection/production wells for the baseline tests. Under the supervision of Robert Swain (AWE), this task is complete.

\section{Drill producer and observation wells}

A new production well and an observation well near the center of the demonstration site were planned, permitted and drilled. The wells were completed and equipped in late 
September. The producer, Well No.101, will be steamed for the baseline tests. The adjacent observation well is equipped for temperature monitoring during the steaming. A core was removed from the producer well with over $80 \%$ recovery. Missing intervals were subsequently sampled with sidewall cores. The cyclic baseline tests are ongoing.

\section{Assembly of digitized log suites}

A project area is defined as the Pru Fee property and a corridor $500 \mathrm{ft}$ in width surrounding the property. Within the project area 135 wells have been identified for which some type of log data is available. Ninety of the wells have digital logs. The location of the wells have been verified and the quality of the logs checked by Mike Simmons of ARCO Western Energy (AWE). Those logs that had not already been loaded into a TerraStation $^{\mathrm{TM}}$ database were added to the project file. Logs not currently in the AWE database have been requested. These additional log suites will be digitized and added to the project database. The existing electronic database was transferred to the other team members responsible for carrying out the stratigraphic analysis.

\section{Development of a stratigraphic framework}

In advance of developing a reservoir model for the Pru Fee demonstration site, the stratigraphy of the project site has been characterized in considerable detail. The goal was to: (a) develop a three dimensional representation of the major sand bodies and intervening barriers, (b) delineate the sedimentary facies and depositional setting, and (c) tie lithologic and petrophysical properties of the rocks to the geometric and depositional framework. Key to developing the stratigraphic model is correlation of log responses in the wells within the project area to the new production well drilled, Pru 101, cored and logged during the latter half of September 1995. The examination of the core included:

- Visual core description of lithology, bedding character and oil staining,

- Routine analyses by Core Laboratories of 246 samples of porosity, permeability and fluid saturations,

- Thin section analysis of 33 samples, of which 17 were submitted for x-ray diffraction (XRD) analysis,

- Sieve and laser particle-size analysis conducted on 10 sand samples of a range of visual textures, and

- A log analysis model of the Monarch Sandstone using PETCOM software to calculate effective porosity, water saturation, non-reservoir volume and permeability.

The project well log files (TerraStation ${ }^{\mathrm{TM}}$ database) that were transferred to Dr. Douglas Sprinkel in Salt Lake City have been examined and correlations made. The stratigraphic analysis is essentially complete.

\section{Reservoir characterization}

Initial "trial" reservoir simulations have been carried out by Dr. Milind Deo and his graduate student Hong Mei Huang to examine model sensitivities for the Pru Fee demonstration site. Using reasonable reservoir properties for the Upper Monarch sand in the Midway-Sunset field provided by Robert Swain of AWE, preliminary simulations were performed to assess the effect of bottom water on cyclic and steam flood processes. The 
geometric parameters match closely what is know known about the demonstration site in the Pru Fee property and conventional AWE production methods. The initial models found that in both the cyclic steam and the steam flood processes, the presence of bottom water decreased production, but not significantly. This was due to heat losses to the water zone. In general, the bottom water has lesser impact on the steam flood process than on the cyclic process. The reservoir simulations are continuing as more site specific data are made available from other team members in the course of the ongoing stratigraphic and reservoir modeling studies.

\section{Literature compilation}

A project bibliography was assembled during the first weeks of the project to assist the project team with reviewing the existing literature dealing with slope and basin clastic (Class III) reservoirs, the regional geology of the southern San Jaoquin Basin, and the petroleum geology of the Midway-Sunset Field and similar oil fields in southern California. The bibliography was developed from GeoRef ${ }^{\mathrm{TM}}$ and the personal libraries of the project team members. It is organized using EndNote ${ }^{\circledR}$ and will be released as part of the overall project database in both an EndNote ${ }^{\circledR}$ and a "rich text" format.

\section{Technology transfer}

At the 1996 annual convention of the American Association of Petroleum Geologists (AAPG) in San Diego, California, May 19-22, the project team presented an invited paper in the session Application of New Technologies to Enhance Oil Recovery. The paper entitled "Integrated, multidisciplinary reservoir characterization, modeling and engineering leading to enhanced oil recovery from the Midway-Sunset field, California" summarized the purpose of the project and the technical results to date.

\section{Tasks Remaining in Budget Period 1}

Remaining to be completed in Budget Period 1 are:

- Stochastic modeling of the Monarch Sand reservoir at the Pru demonstration site and upscaling in preparation for reservoir simulation.

- Development of a site-specific 3D simulator for the Monarch Sand reservoir and testing of a variety of production modes and parameters.

- Development of a production plan for the Pru pilot demonstration.

- Placement of a public database for this project with the Bakersfield office of the California Department of Oil, Gas and Geothermal Resources (DOGGR).

- A public workshop in Bakerfield, California presenting the major results of this project to operators in the southern San Joaquin Basin and other areas in California. 


\section{Chapter 2}

\section{Core Description and Petrophysical Analysis of Pru 101}

\section{Introduction}

The Pru 101 well was cored to obtain additional information about rock quality and fluid saturations on the Pru lease. Specifically, the well was cored to:

- determine reservoir quality ( $\mathrm{Sw}$, permeability, net-to-gross, porosity)

- understand the controls on reservoir quality (grain size, sorting, mineralogy, clay volume)

- $\quad$ assess the number and quality of steam barriers (permeability, thickness, lateral extent)

- develop a log model to calculate rock properties and saturations in uncored wells

- compare reservoir quality with offset wells including the Kendon 405 and Pru 533.

Several types of core data were analyzed to characterize the reservoir including:

- A visual core description to characterize the lithofacies present in the core, their relationship to one another, and their depositional environment.

- Routine core measurements to understand (1) the distribution of porosity, permeability, and fluid saturations in core and (2) how to use these values for calibrating the log saturations.

- X-ray diffraction to identify and quantify the minerals present in the whole rock and clay fractions.

- Thin-section descriptions to characterize pore geometries, controls on reservoir quality, and susceptibility to formation damage.

The core data were then related to the logs through:

- A petrophysical analysis of the reservoir to calculate porosity, permeability, and saturations in uncored wells.

Finally, the data were used to make projections about reservoir performance through:

- An analysis of sand and barrier continuity to assess the connectivity of sands and lateral extent of steam barriers.

- An assessment of water saturation and well performance with special emphasis on the impact of a transition zone in the reservoir.

\section{Visual Core Description}

A total of 225' of core recovered from the Pru 101 well was described in Bakersfield during October, 1995. The core is dominated by poorly to very-poorly sorted, massive to 
pebbly, oil-stained sands and is divisible into six lithofacies types, summarized below. The percentage of each lithofacies observed in the core is indicated in brackets.

- Pebble sands [10\%] contain 10-15\% granules and 10-40\% pebbles with occasional cobbles up to 4 by 4 inches in size. All of the sands are matrix-supported with clasts of subangular-to-subrounded plutonic, volcanic, and metamorphic rocks that have the same aggregate mineralogy as the matrix sand. Intervals consisting only of pebbles and cobbles are inferred to be pebble sands that have had their matrix sand washed away during coring. Graded bedding and pebble imbrication are rare.

- Granule sands [16\%] contain 10-25\% granules and 5-20\% pebbles. Some intervals contain faint laminae dipping up to 20 degrees. Granule sands are distinguished by a co-equal percentage of granule and pebble-sized rock clasts and less intense pebbling.

- Coarse-grained sands [43\%] contain 5-20\% granules and $<5-20 \%$ pebbles. Large pebbles and thin layers (1-2 inches) of intense pebbling are occasionally seen. Sedimentary features include siltstone rip-up clasts, imbricated clasts, inclined and horizontal bedding, thin siltstone interbeds, and carbonaceous material. Coarse sands are characteristically massive with small, widely-dispersed pebbles.

- Medium-grained sands [27\%] contain $<5-15 \%$ granules and $<5 \%$ pebbles. Sedimentary features include thin interbedded siltstone and fine sand layers which often have basal lags of granules and carbonaceous material, rip-up clasts, and faint horizontal to gently dipping laminae. Medium-grained sands are characterized by a distinctly finer grain size than other productive sands and a near absence of pebbles.

- Muddy to bioturbated fine sands [4\%] range from mottled, bioturbated, oil-stained sand and mudstone in the Etchegoin Formation (overlying the Monarch) to tan, lightly oil-stained, siltstone and fine micaceous sand within the Monarch. Sedimentary features include horizontal to inclined burrows, carbonaceous fragments, and interbeds of medium-grained sand. These sands are distinguished by their bioturbation, light oil staining, large silt/clay fraction, and permeabilities that are lower than productive sands. Within the Monarch, there are 17 different intervals of this lithofacies, ranging from 0.1-0.6 ft in thickness.

- Mudstones form gray, unstained, massive to laminated intervals primarily in the overlying Etchegoin Formation. Sedimentary features include inclined burrows, calcareous pebbles, and conjugate faults with very minor displacement.

After dividing the core into lithofacies types, a histogram was created to show the vertical changes in these lithofacies and facilitate their grouping into fining and coarsening upward sequences. The histogram is dominated by fining-upward sequences that can be subdivided into individual turbidite flows. For example, the sequence from 1230.6-1240.7 $\mathrm{ft}$ is composed of three individual turbidites: (1) a pebble sand to medium-grained sand from 1240.7-1235.3 ft, (2) a coarse sand to medium grained sand from 1232.3-1235.3 ft, and (3) another coarse sand to medium grained sand from 1230.6-1232.3 ft. Applying this technique to each fining-upward sequence yields a mean thickness of $2.3 \mathrm{ft}$ for individual turbidites in the Monarch with a range of 0.1 to $6.3 \mathrm{ft}$. 
Inverse grading occasionally generates a coarsening-upward sequence between finingupward sequences. However, the dominance of fining upward sequences combined with diagnostic aspects of the core (massive to parallel laminated sands, rip-up clasts, thin suspension deposits, flame structures, low clay content) confirm that the Monarch was deposited as a series of high-density turbidites. Overall, the sequence coarsens-upward from the oil-water contact to the top of the Monarch. This is clearly shown by a decrease in the amount of coarse and medium grained sands above about $1285 \mathrm{ft}$. This change is consistent with a prograding shoreline and progressive filling of the basin.

The proposed depositional model is a steep-faced fan-delta prograding onto a shallow marine shelf. Periodic remobilization of fan-delta deposits (probably debris flows) generates turbidity currents that flow downslope to deposit the Monarch Sand. The muddy fine sands capping many of the turbidites are deposited from suspension as the flow wanes. The absence of any true marine clays (pelagic or hemi-pelagic) indicates short periods between successive turbidites.

The interpretation presented here compares favorably with the conclusions of Webb, 1978. He states that the Monarch in T32S, R23E, Section $26 \mathrm{C}$ is composed of turbidites ranging from 0.3-5 ft thick with an average thickness of $2 \mathrm{ft}$. Webb identifies the presence of "diatomite" layers composed of diatoms and fine-grained clastics which are equivalent to the muddy to bioturbated fine sands described in this study. He also describes the Monarch as an overall coarsening-upward sequence generated by a prograding fan.

\section{Analysis of Routine Core Measurements}

Routine core measurements were made by CoreLab on 246 samples using a confining pressure of 500 psi, which approximates the net effective overburden stress in the reservoir. A cross-plot of permeability vs. porosity using these core measurements shows that each lithofacies occupies a specific field. Pebble sands show a large amount of dispersion because the dominant heterogeneity (pebbles) is often larger than the sample size of the core plug (about 1.5 inches). Granule and coarse-grained sands show progressively higher porosities and permeabilities as a result of fewer pebbles and little clay. Medium-grained sands have higher porosities due to better sorting but lower permeabilities due to finer grain size and the inclusion of suspended clays.

Bioturbated to muddy sands display permeabilities which are at least two orders-ofmagnitude lower than productive sands. This should be sufficient to make these finegrained, clay-rich rocks barriers to vertical steam migration if they are sufficiently thick and laterally extensive. Porosities reported for the mudstones and bioturbated to muddy sands $(31-51 \%)$ reflect the high micro-porosity of these samples.

Water saturation $(\mathrm{Sw})$ and oil saturation (So) values from the core are of limited value due to the drainage of liquid from samples, possible invasion during coring, and transition zone penetration. However, some statistics are still useful, especially the $\mathrm{Sw}$ minimums which are about $16 \%$ for coarse and granule sand, $18 \%$ for medium sand, and $20 \%$ for pebble sand. These values follow the same trend as the permeability distribution and 
provide a good indication of irreducible water saturation (Swirr). Similarly, the So minimums of around $13 \%$ provide a good measure of Sor.

\section{Analysis of X-Ray Diffraction Data}

In order to relate sand quality differences in the Pru 101 well to differences in whole rock and clay mineralogy, 17 samples were chosen for X-ray diffraction (XRD). The results of this work show that productive sands have an average composition of $36.8 \%$ quartz, $16.8 \%$ potassium feldspar, $37.0 \%$ plagioclase feldspar, $7.4 \%$ biotite, $0.5 \%$ pyrite, and $1.6 \%$ clay. Productive sand samples have moderate amounts of clay + biotite $(4.7$ to $15.7 \%$ ) which increases with decreasing grain size and permeability. The gross abundance of quartz, plagioclase and potassium feldspar remains relatively constant irrespective of grain size. This suggests that the individual mineral grains in the finer-grained rock types were derived from the same parent rock as the rock fragments in the coarser-grained sands.

The muddy to bioturbated fine sand and mudstone samples have substantially more clay (31.9 to $41.4 \%$ ) and pyrite (4.5 to $4.8 \%$ ) than the productive sands. The clays are composed of mixed-layer illite-smectite, chlorite, and trace amounts of kaolinite. Samples from an oil-depleted zone in the well (1102-1113 ft) show a slight increase in illitesmectite at the expense of chlorite and biotite. This is probably a diagenetic alteration caused by steaming (Pennel and Horton, 1994).

There appears to be a rather poor relationship between permeability and \% clay, largely because all of the productive sands have such a low percentage of clay. However, the relationship between permeability and \% biotite + clay is significantly better. Sands with permeabilities below 1000 md can be expected to have $>15 \%$ biotite + clay.

\section{Analysis of Thin-Sections}

Thin-sections were cut from 33 samples and evaluated to assess reservoir quality and formation damage potential. The results of this work show that samples with the highest reservoir quality are matrix-poor sandstones that combine the most open packing, best sorting, and coarsest mean grain size. Pore geometries in these sands are dominated by well-connected interparticle macropores.

Grain size, sorting, and rounding indicate post-depositional crushing of feldspars. This results in fine grained, extremely angular fragments especially in medium- to coarsegrained sandstones. The presence of these fragments introduces a significant fine tail to the grain size distribution and indicates that these rocks are highly susceptible to fines migration. In contrast, crushing is minor in matrix-rich samples, probably because the matrix provided support for the grains and helped dissipate stresses at grain-to-grain contacts.

Chemical diagenesis in sands is minor and is generally limited to (1) alteration of volcanic rock fragments to chlorite and smectite, (2) local dissolution of unstable framework grains, and (3) expansion and alteration of biotite flakes to chlorite, smectite, and pyrite. These processes should have a minor affect on productive sands due to their 
large pore throats and the relatively small amounts of clay $(<4 \%)$ and reactive minerals (biotite and volcanic rock fragments) available for conversion to smectite.

Mudstones and bioturbated to muddy fine sands contain abundant clay present as detrital matrix and alterations of rock fragments. These sands also contain trace to minor amounts of sponge spicules and diatoms. Pore geometries are dominated by interparticle micropores that are substantially smaller than productive sand pores.

\section{Petrophysical Analysis}

A log analysis model for the Monarch Sand on the Pru lease was developed to calculate effective porosity, water saturation, non-reservoir volume, pebble volume, and permeability. The model can be applied to any well with a minimum logging suite of resistivity, density, and neutron curves. Information from the model will help (1) determine the net hydrocarbon feet available for production and (2) extract lithofacies information that can be used to make decisions about steam flooding or cycling wells. The model was calibrated to depth-shifted core from the Pru 101 well; it also was applied in the nearby Pru 533 well as a check.

Porosity: As discussed previously, core porosities were measured at net effective overburden stress (500 psi) and should approximate reservoir conditions.

1) To calculate the density porosity use:

$$
\phi_{\mathbf{d}}=\left(\rho_{m a}-\rho_{\log }\right) /\left(\rho_{m a}-\rho_{f}\right)
$$

where: $\quad \rho_{\log }=$ bulk density from the $\log$

$\rho_{\text {ma }}=$ matrix density of $2.69 \mathrm{gm} / \mathrm{cc}$ from XRD results

$\rho_{\mathbf{f}}=$ fresh water fluid density of $1.0 \mathrm{gm} / \mathrm{cc}$

2) In undepleted intervals calculate the effective porosity using an average of the neutron and density:

$$
\phi_{\mathrm{e}}=\left(\phi_{\mathrm{d}}+\phi_{\mathrm{n}}\right) / 2
$$

where: $\phi_{\mathbf{d}}=$ density porosity in decimal fraction

$\phi_{\mathbf{n}}=$ neutron porosity in decimal fraction

3) In the oil-depleted intervals the neutron porosity will be too low and the density porosity will be too high. Depleted intervals are defined here as those in which the density porosity reads higher than the neutron by more than $3.0 \mathrm{pu}$. When this condition is met, the following equation should be used to calculate effective porosity:

$$
\phi_{\mathrm{e}}=\left(0.66 * \phi_{\mathrm{d}}\right)+\left(0.33 * \phi_{\mathrm{n}}\right)
$$


Water Saturation: Determination of water saturation was greatly aided by coring and logging the aquifer. Formation water resistivity $(\mathrm{Rw})$ was determined by direct measurement of water extracted from the core and a cementation exponent $(\mathrm{m})$ was calculated from the logs in the aquifer. In addition, the log model was matched to core from both the aquifer $(100 \% \mathrm{Sw})$ and the top of the reservoir (Swirr), lending confidence that the saturation model between these two points is accurate. This is important because through the transition zone of the Monarch both oil and water are lost from the core, making it difficult to accurately calibrate log saturation values.

Because of the low clay volume, there is little difference between a shaly sand equation, such as the Simandoux, and the Archie equation. Therefore, the Archie equation, which is also much simpler, was applied to the Monarch Sand in this study. The log model does not perform as well in the depleted zone due to the variable Rw caused by the presence of steam and condensed steam.

$$
\mathbf{S}_{\mathbf{W}}=\left(\frac{R_{w} * a}{R_{t} * \phi_{e}{ }^{m}}\right)^{\frac{1}{n}}
$$

where: $\quad \mathbf{R}_{\mathbf{w}}=$ the formation water resistivity $(0.55 @ 77 \mathrm{oF})$

$$
\begin{aligned}
\mathbf{a} & =1.0 \\
\mathbf{R}_{\mathbf{t}} & =\text { Deep Resistivity } \\
\boldsymbol{\phi}_{\mathbf{e}} & =\text { Effective Porosity } \\
\mathbf{m} & =1.80 \\
\mathbf{n} & =1.80
\end{aligned}
$$

Bulk Volume Water: Bulk volume of water (BVW) is defined as the quantity of formation water present in a unit volume of rock.

$$
\text { BVW }=\text { Sw } * \text { PHIE }
$$

On the Pru lease. it is estimated that there is no water production where BVW is less than 0.12 ; possible water production where $\mathrm{BVW}$ is between 0.12 and 0.18 ; and water production when BVW is greater than 0.18. Using these values as cutoffs, $131.5 \mathrm{ft}$ of the Monarch in Pru 101 is below a BVW of 0.12 and $230.5 \mathrm{ft}$ is below a BVW of 0.18 .

Non- Reservoir Rock Volume: The XRD data show that there is less than $3.5 \%$ clay in the Monarch Sand. Because this small amount is difficult to resolve with the logs, the clay volume was combined with the silt volume into a single "non-reservoir rock" volume. This technique identifies those intervals of lower quality that are unlikely to contain economic oil saturation. The neutron porosity was chosen as the most reliable indicator of non-reservoir rock because of the difficulty in using a GR (feldspathic sands) or SP (little contrast between borehole and formation waters) in these sands.

$$
\mathrm{V}_{\mathrm{nr}}=\left(\phi_{\mathbf{n}}-\mathbf{0 . 3}\right) / \mathbf{0 . 1 5}
$$


$\begin{array}{ll}\text { where: } & \mathbf{V}_{\mathbf{n r}}=\text { Volume of Silt }+ \text { Volume of Clay } \\ & \phi_{\mathbf{n} \geq 0.30} \\ & \text { Deep Resistivity } \Leftarrow 20 \text { ohm-meters } \\ & \text { Shallow Resistivity } \Leftarrow \text { Deep Resistivity }\end{array}$

Pebble Volume: It is helpful to know the location of pebbly intervals in a well because these may help slow the upward movement of injected steam and they also have a lower recovery per unit volume. As pebbles increase in the reservoir, porous sands are replaced with dense pebbles, decreasing porosity. As a result, the pebble volume equation developed for the Monarch Sand uses density porosity as shown below.

$$
V_{\text {peb }}=\left(\left(\phi_{\mathrm{d}} * 100\right)^{-4.452}\right) *\left(10^{4.68}\right)
$$

when: $\quad \rho_{b} \geq 2.23 \mathrm{gm} / \mathrm{cc}$

Permeability: As discussed previously, permeability is a function of grain size, sorting, and clay content in the Monarch. Given these controls, it is difficult to accurately calculate permeability from the logs. Logs do not make direct measurements of grain size and sorting, and they are unable to accurately resolve the small changes in clay content that cause large changes in permeability. Therefore, in this study, permeability was determined using values of $\mathrm{Sw}$, porosity, and the volume of silt + clay calculated from the logs. Since all three of these parameters have a strong dependence on permeability, combining them into a single equation provides a reasonable permeability indicator. A Wyllie permeability equation (Slider, 1983) was modified and used here.

$$
\text { PERM }=\left\{\left[200^{1-(V n r * 0.7)}\right] *\left[\phi_{e}^{2.25} * \frac{(1-S w i r r)}{\text { Swirr }}\right]\right\}^{2}
$$

where: $\quad$ Vnr $=$ Volume of Non-Reservoir Rock (Vsilt + Vclay $)$

$\phi_{\mathbf{e}} \quad=$ Effective Porosity

$\mathbf{S}_{\text {wirr }}=$ Irreducible Water Saturation

$\mathbf{S}_{\text {wirr }}$ is 0.20 from the whole core analysis.

\section{Sand and Barrier Continuity}

Ideally, for efficient steamflooding, periods of sand deposition will be separated by long quiescent periods during which laterally-extensive muds can be deposited to form steam barriers. Unfortunately, this did not occur during Monarch deposition, and only thin, 
laterally discontinuous suspension deposits, which formed during waning turbidite flow, serve as potential barriers.

These suspension deposits will only be actual barriers where (1) they are thick enough to survive erosion by successive sand flows, and (2) have permeabilities that are about two orders of magnitude less than productive sands. Webb (1978) identified such an interval in the Monarch Sand of Section 26C. Core from this area contains about $5 \mathrm{ft}$ of silicacemented sands and thick "diatomites" (muddy fine sand deposited from suspension) with permeabilities of 2-3 md. These are interbedded with oil-stained sands over a thickness of 8-10 ft. Webb indicates that this interval can be correlated on logs and extends over an area at least 600 by $1000 \mathrm{ft}$. Steam injected beneath this "marker zone" remained below it based on data from temperature observation wells.

Unfortunately, no zones of similar thickness and low permeability were observed in the Pru 101 core. However, the log model does indicate one potential steam barrier through which no core was recovered. This interval, from 1208-1218 ft, is characterized by 4095\% silt and clay and probably consists of interbedded muddy fine sand and mediumgrained sand. This interval may only be present over a small area because it is not apparent in the neighboring Pru 533 well.

\section{Water Saturation and Well Performance}

At the top of the Monarch reservoir in Pru 101 is a $14 \mathrm{ft}$ thick oil-depleted interval that has a distinctly lighter oil stain than the underlying sand. This zone, which is also characterized by high permeabilities, low oil saturations, and neutron-density crossover on the logs, grades into the underlying undepleted zone over a distance of several feet. At the base of the reservoir, a sharp oil-water contact separates the oil sand in the Monarch from the underlying aquifer.

From the base of the oil-depleted zone to the oil-water contact, core and log data indicate a progressive increase in $\mathrm{Sw}$. This is due to the presence of a long transition zone as indicated by a plot of core Sw (for samples with total liquids $>90 \%$ ) vs. height above the oil-water contact by permeability band. Intuitively, the transition zone here should be short due to the high sand permeability. Capillary pressures of only 1 psi or so should result in irreducible water saturations (Swirr). Unfortunately, it takes over a hundred feet of rock column to obtain this pressure due to the small density difference between heavy oil (12 degrees API) and water (10 degrees API) in the reservoir. Using the equation Howc $=(\mathrm{Pc} /(.433 *$ rbrine - roil $)$ where rbrine $=1.0 \mathrm{~g} / \mathrm{cc}$ and roil $=0.98 \mathrm{~g} / \mathrm{cc}$, then at a capillary pressure $(\mathrm{Pc})$ of 1 psi, Howc $=115$ feet.

Figure 9 also includes approximate resistivity (Rt) values corresponding to the $\mathrm{Sw}$ values displayed along the X-axis. This scale shows, for example, that Rt is only $35 \mathrm{OM}$ at $30 \%$ Sw. However, at $20 \% \mathrm{Sw}$, Rt has more than doubled to $75 \mathrm{OM}$. This accounts for the apparent "step-change" in Rt above about $1220 \mathrm{ft}$ on the logs. This explanation also means that above $1220 \mathrm{ft}$, the reservoir should be near Swirr and have water free initial production. This is supported by bulk volume water values below 0.12 . Below $1220 \mathrm{ft}$, there will be a substantial loss of heat and a progressive increase in water production due 
to the increase in mobile water. This, coupled with lower oil saturations, will negatively impact steamflood economics in the bottom half of the reservoir.

\section{Conclusions}

1. Above the oil-water contact is a 150-foot transition zone that exists because of the small density difference between heavy oil and water in the reservoir. This transition zone contains mobile water which will absorb heat and be produced along with the oil. From the top of the reservoir (1100 ft) to about $1210 \mathrm{ft}$ depth, water saturations are near irreducible and initial production should be water-free.

2. The only interval in the well that may be a laterally continuous steam barrier is from 1208 to $1218 \mathrm{ft}$. This interval is likely composed of interbedded muddy fine sand and medium-grained oil sand, although no core was recovered through it.

3. $96 \%$ of the core recovered from the Monarch consists of oil-stained sand. This includes $27 \%$ medium-grained sand, $43 \%$ coarse-grained sand, $16 \%$ granule sand, and $10 \%$ pebble sand. The remaining $4 \%$ of the core is comprised of non-reservoir mudstone and muddy to bioturbated fine sand.

4. Effective porosity, water saturation, non-reservoir rock volume, pebble volume, and permeability calculated using the Monarch Sand log model compare very well with core. The model, developed in this study using an AIT/LDT/CNL/GR tool suite, can be applied to any other Monarch Sand well with a resistivity, density, and neutron log.

5. The AIT logging tool recorded significantly higher resistivities from 1100-1210 ft in Pru 101 relative to offset wells with older standard dual induction (ILD) logs. Modeling indicates that shoulder-bed effects could explain the discrepancy over the top $12 \mathrm{ft}$ of this interval, but cannot account for the entire interval. The higher resistivities result in a decrease of 5-10 saturation units relative to offset wells. Based on in-house discussions and industry consensus, the AIT should be more accurate than the older ILD.

6. X-ray diffraction (XRD) data show that the mineralogic composition of productive sands is fairly uniform and consists of quartz (36\%), plagioclase (36\%), K-feldspar (17\%), biotite $(9 \%)$, pyrite $(1 \%)$, and clay $(1 \%)$. The feldspar grains and rock fragments have been crushed into mobile fines that could cause plugging or "flour sand" production, especially at high flow rates.

7. Visual inspection of the log curves from Pru 101 and Pru 533 indicates that resistivities less than about $13 \mathrm{ohm}$-meters are definitely non-reservoir. These intervals include both silty sands and higher quality wet sands, as well as mudstones. A review of the log curves from Pru A-2, Pru 13, and Pru A-5 indicate that a similar cut-off is applicable in these wells.

8. The sands were deposited as turbidites and minor, associated debris flows based on the suite of sedimentary structures observed in core and the arrangement of sands into a series of fining-upward sequences. Given the high net-to-gross (0.96) observed in Pru 101 core, reservoir continuity likely will be excellent. However, steam barrier continuity will be poor because potential barriers are thin and commonly eroded by successive turbidite flow units. 


\section{Chapter 3}

\section{Stratigraphic Model}

\section{Introduction}

The Midway-Sunset field produces from multiple reservoirs that range in age from Oligocene to Pleistocene; most of the oil is produced from the Upper Miocene reservoirs (Hall and Link, 1990). The reservoir at the ARCO Western Energy Pru Fee property is the Upper Miocene Monarch Sand.

The stratigraphic nomenclature applied to this part of the Midway-Sunset field is a combination of formal units, which are recognized at the surface and in the subsurface, and informal units, which are identified mostly in the subsurface. The stratigraphic nomenclature of Callaway (1962) and Foss and Blaisdell (1968) has been adopted in this project as it is the nomenclature in most common use in the field. The Monarch Sand is an informal unit within the Antelope Shale member of the Monterey Shale. It typically overlies the informal Republic, Williams, and Leutholtz sands (in descending order). The Monarch Sand normally is overlain by the upper part of the Antelope Shale and the Reef Ridge Shale. However, at the location the Pru Fee property on the SW flank of the Spellacy anticline a regional unconformity removes the Reef Ridge Shale and the top of the Antelope Shale placing the Pliocene Etchegoin Formation directly on the Monarch Sand. Although no well has penetrated below the Monarch Sand at the project area, there is reason to believe that the underlying stratigraphic section is similar to that of nearby areas.

The stratigraphic model for the Monarch Sand reservoir in the project area was developed using geophysical logs, core descriptions, outcrop observations of comparable units, and petrophysical data from core plugs. There are 143 wells in the project area, of which 33 are within the Pru Fee property (Fig. 3.1). About 80\% of the log suites were suitable for identifying and correlating stratigraphic units within the Monarch Sand. However, there were only three cores available in this phase of the project, ARCO wells Pru 101, Pru 533, and Kendon 405 located immediately west of the Pru property. All three cores have quality lithologic descriptions and petrophysical data.

\section{Stratigraphic Analysis}

Stratigraphic divisions recognized in the Pru 101 and Pru 533 cores and reflected in log response, particularly in conductivity, deep resistivity, and gamma ray logs (Fig. 3.2), were correlated throughout the project area. Five surfaces could be correlated with a reasonable degree of confidence between most of the wells At least two of the surfaces (1 and 3) appear to correspond to laterally continuous or semi-continuous non-reservoir units that might serve as a barrier or baffle to steam injection. The procedure for selecting and correlating stratigraphic units is diagrammed in Figure 3.3. 
Pru Project Area, Midway-Sunset Field

T. 32 S., R. 23 E., Kern County, California

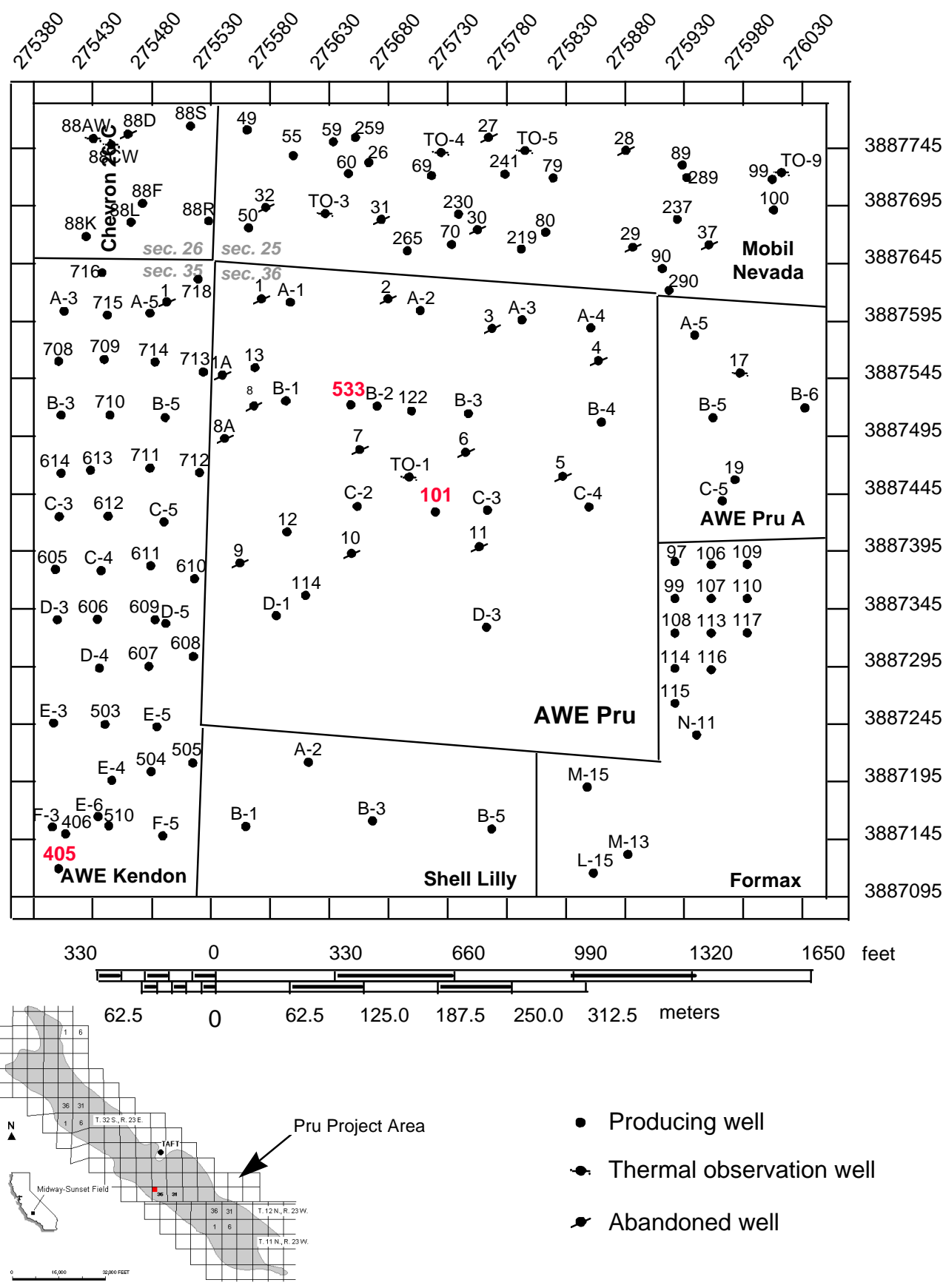

Figure 3.1: Pru project area within the Midway-Sunset field. Core descriptions and petrophysical data were only available for three wells: the ARCO Western Energy (AWE) Pru 101, the AWE Pru 533, and the AWE Kendon 405. Map coordinates are in UTMs, zone 11. North is to the top of the figure. The Pru base map was created using TerraStation and was extensively modified outside of the TerraStation environment. 


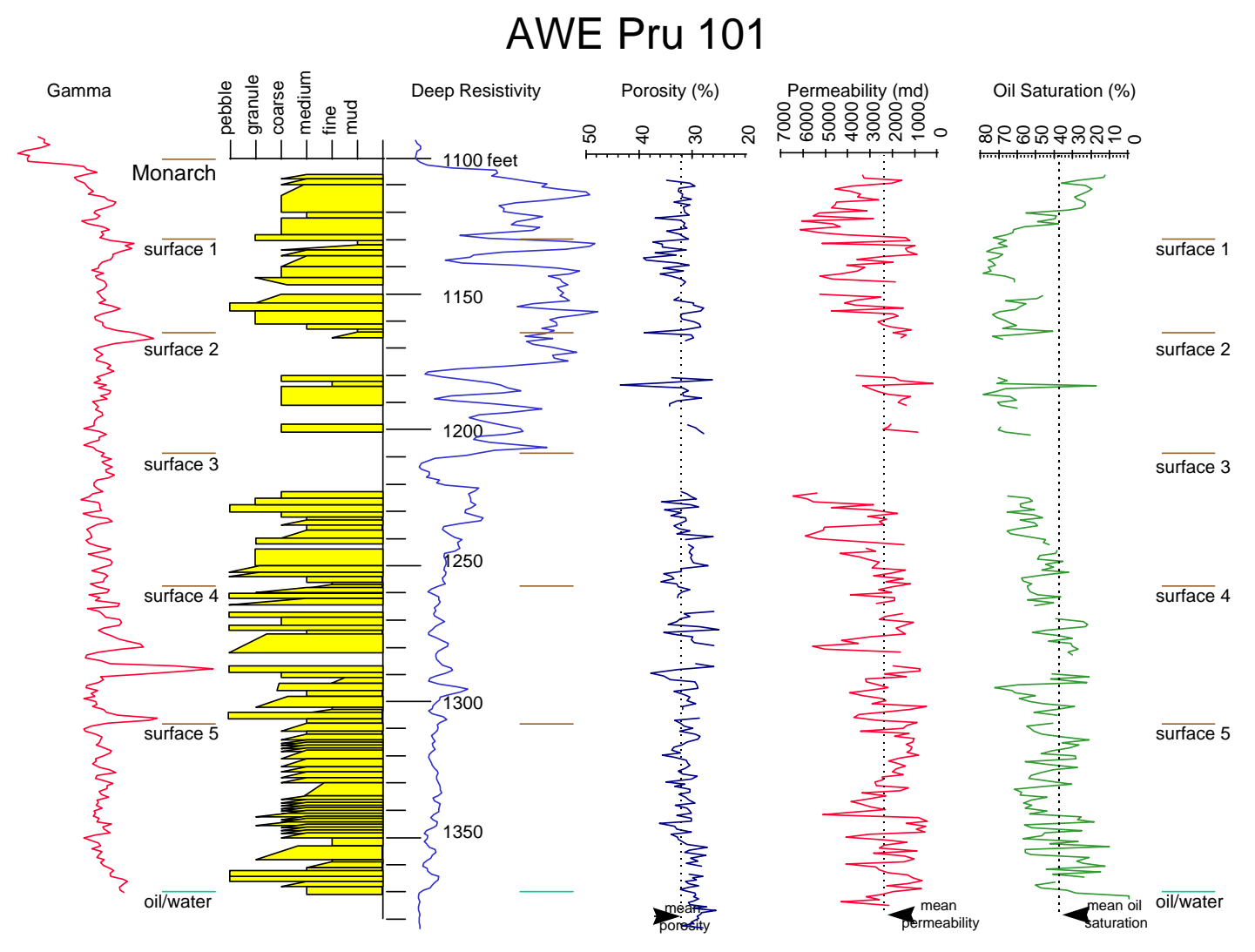

Figure 3.2: Diagram of stratal patterns, petrophysical, and geophysical log data from the Pru 101 core. Stratal patterns indicate that the grain size and bed thickness are generally increasing upward, which suggests a shoaling upward of the Monarch sand in the Pru 101. Note the high gamma ray response at 1,290 feet and 1,306 feet. These two gamma ray spikes correspond to igneous cobbles within matrix-supported beds. Surface 3 may be the only barrier within the homogeneous Monarch. Although no core was recovered across surface 3, the geophysical logs indicate significant change in oil saturation. Surface 3 marks the top of a thick water-saturated transition zone and a change from distal slope (mid fan) deposition to shallower slope (upper fan) deposition. 


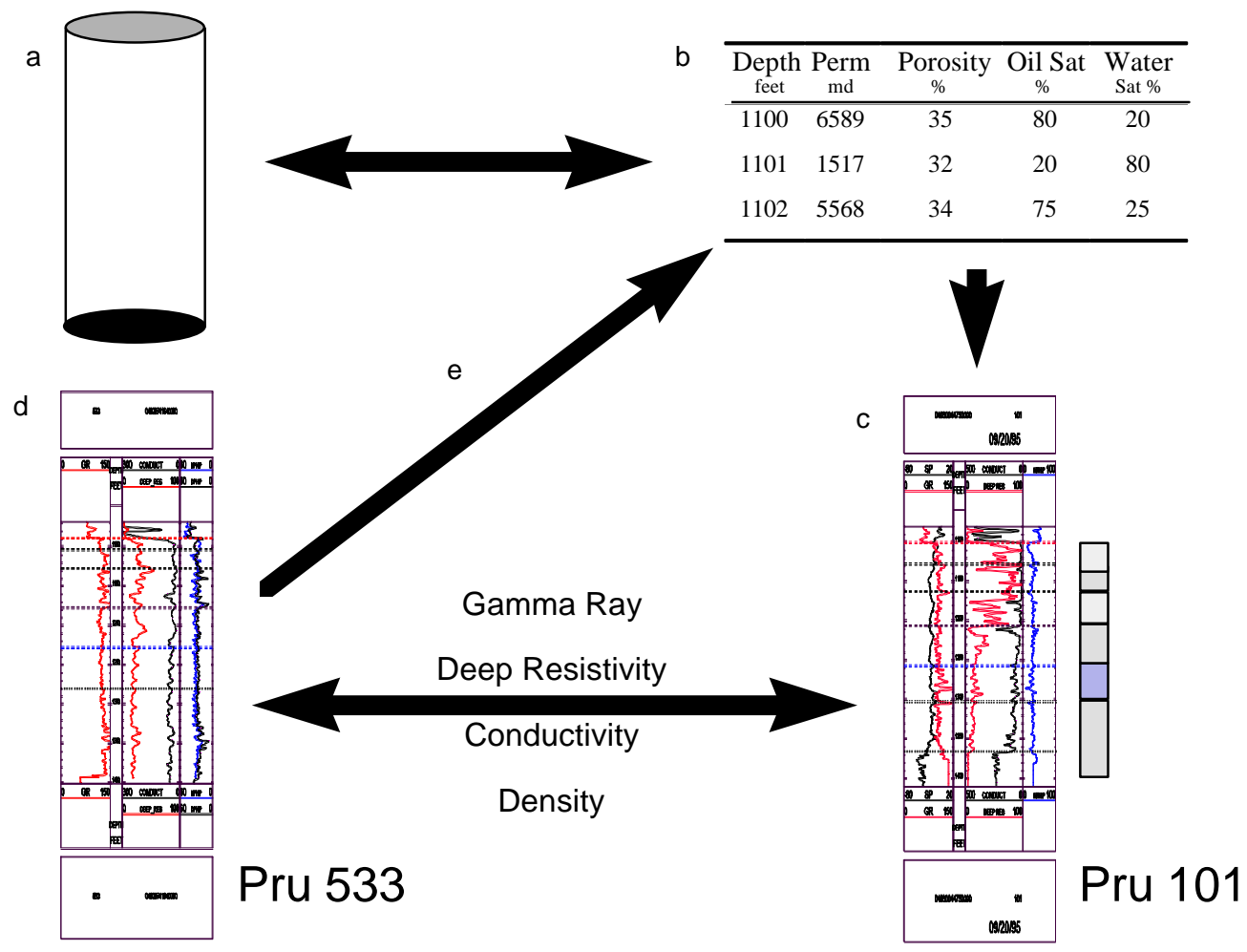

Figure 3.3: The process used to define the internal stratigraphy of the Monarch sand. (a) Core from the Pru 101was described and a graphic section of the core's grain sizes and bed thickness was constructed. (b) Core analysis was reviewed noting the depths where permeability decreased by at least two times. The permeability changes generally correlated with fine-grain and muddy and bioturbated sandstone. (c) Permeability changes were compared to changes in gamma ray, deep resistivity, and conductivity responses on the geophysical logs. In general, the permeability changes corresponded to increased gamma, decreased resistivity, and increased conductivity. The changes were marked as surfaces that may represent barriers or baffles. Five surfaces were identified in the Pru 101 well as surfaces 1 through 5, in descending order. Characteristic geophysical log patterns of sedimentologic or flow units were recognized between the surfaces. (d) Five surfaces were correlated with the Pru 533 well using geophysical logs. (e) The depths of the five surfaces within the Pru 533 well were compared to the well's core data. Similar to the Pru 101, the surfaces in the Pru 533 corresponded to permeability changes. The geophysical logs were created using TerraStation and were reformatted outside of the TerraStation environment. 


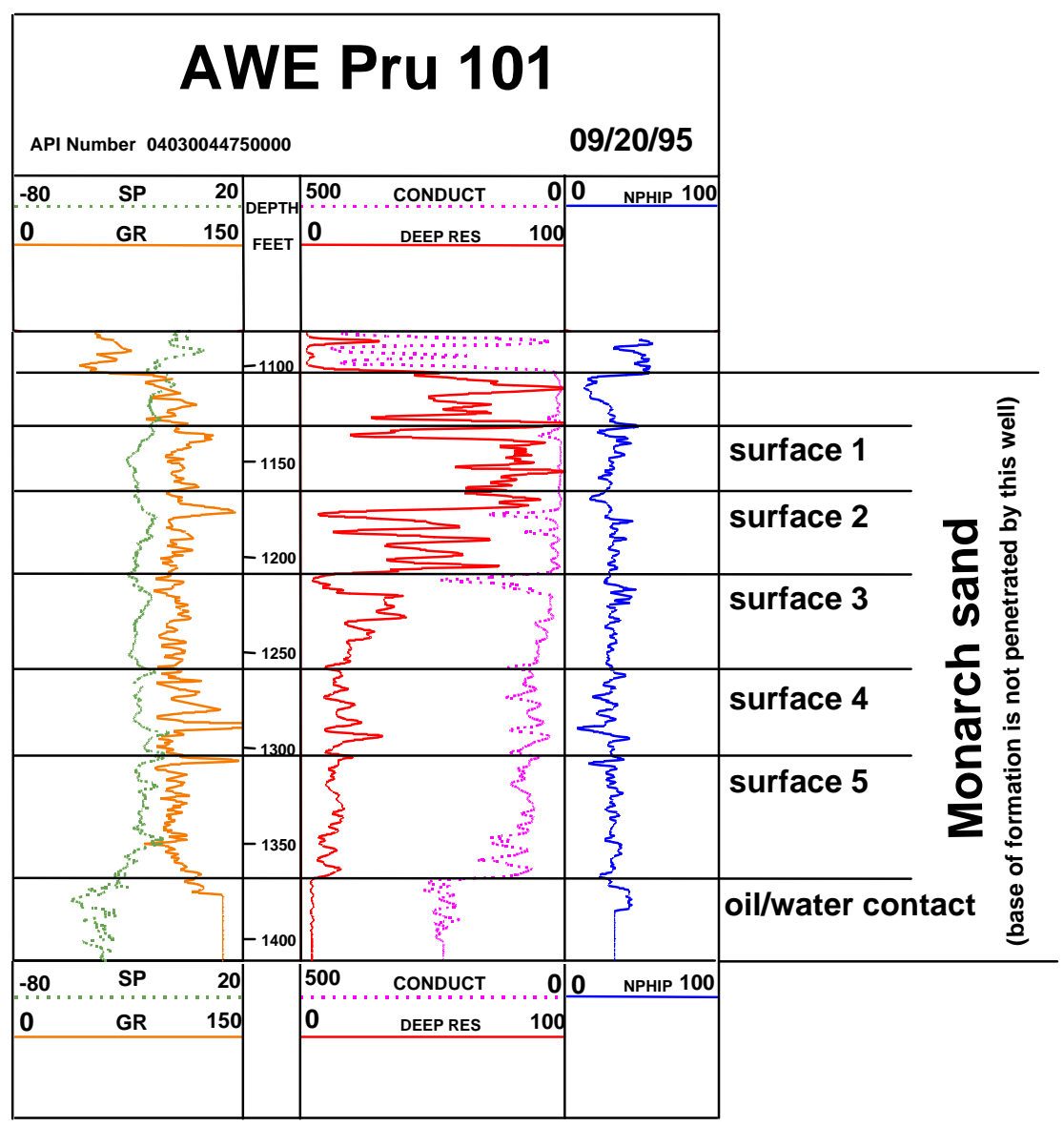

Figure 3.4: Geophysical log of the Monarch sand from the AWE Pru 101. The geophysical log was created using TerraStation and was extensively reformatted outside of the TerraStation environment. 
The stratigraphic analysis of the Monarch sand was based on stratal characteristics from the Pru 101 core, changes in the corresponding petrophysical properties, and geophysical $\log$ patterns in the Pru 101. The integrity of the stratigraphic characterization was tested by correlating the Pru 101 well with comparable data from the Pru 533 (Figure 3.4).

Correlation surfaces 1, 2, and 3 are recognized in all wells, whereas surfaces 4 and 5 are not. The lithologic assemblage, grain size, bed thickness, and other sedimentologic features of the stratigraphic unit between surfaces 4 and 5 in the Pru 101 well suggests it was deposited as a series of amalgamated debris flows. Individual debris flow units can not be correlated, only an irregular zone that is rich in cobbles and pebbly sands, as indicated by the well log response. Although a concentration of debris flows are found in this zone, individual debris flows are recognized elsewhere in the Pru 101 core and in the log response of nearby wells.

Thickness of the Monarch Sand gross pay (top of Monarch to the oil/water contact) decreases southeastward across the project area from about 440 feet in the northwest to less than 100 feet in the southeast (Fig. 3.5). This trend also is reflected in the thickness patterns of the individual stratigraphic units. A dip cross section (B-B') shows that most stratigraphic units thin to the southeast (Fig. 3.6). However, a strike (southwest to northeast) cross section shows limited variations in unit thickness (Fig.3.7). Local thinning of some flow units in the northern part of the project area may reflect paleotopography. The unusual contour pattern in the southeastern part of the gross pay contour map (Fig. 3.5) reflects artifacts of the contouring routine resulting from limited well control in this area.

The Monarch Sand within the project area, which is on the SW flank of the Spellacy anticline, is gently folded by a low-amplitude syncline that plunges southeastward (Fig. 3.8). The top of the Monarch is about 440 feet above sea level in the northwestern part of the project area and about 100 feet above sea level in the southeastern part. 


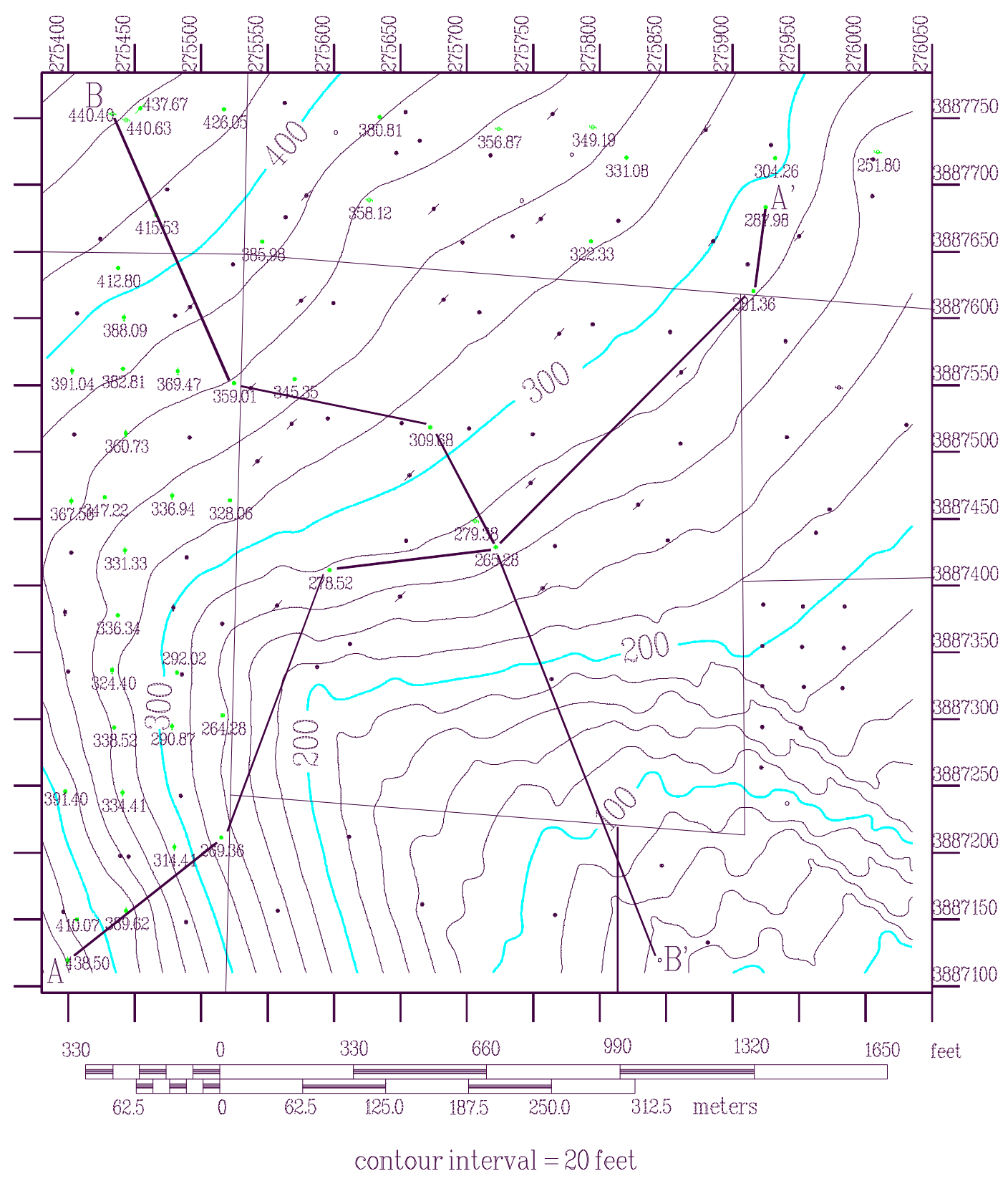

Figure 3.5. Isochore map of the Monarch gross pay and location of cross section lines. The gross pay thins from about 441 feet in the northwestern part of the Pru project area to a projected 100 feet in the southeast. The unusual contour pattern in the southeastern part of the study area reflects the way the contouring software handles the limited data. Coordinate system is in UTMs, zone 11. North is to the top of the figure. This figure was created using TeraStation and was extensively reformatted outside of the TerraStation environment. 


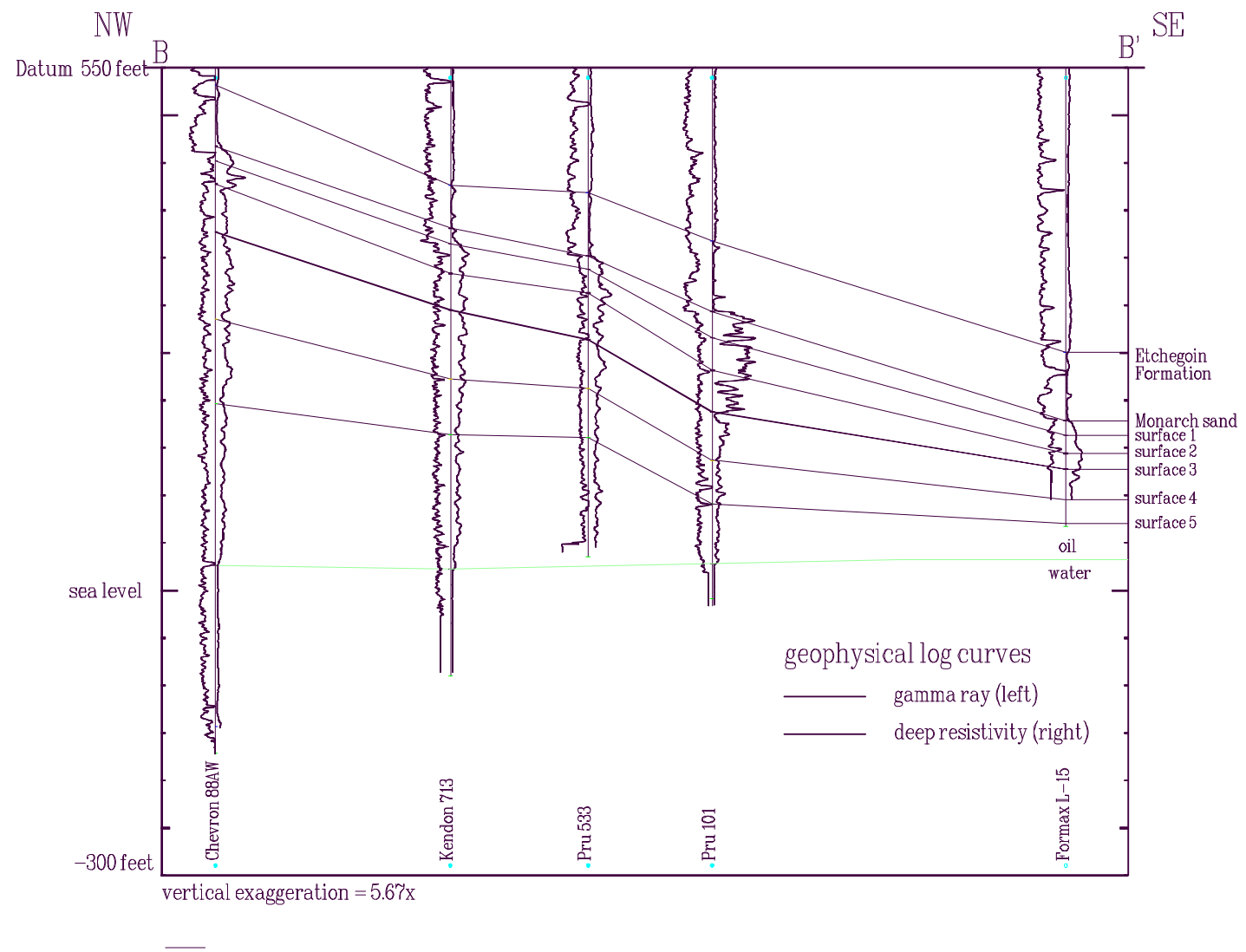

Figure 3.6. Structural cross section B-B' showing the southeast dip of the Monarch reservoir. The thinning pay zone is caused by the structural dip of the reservoir $\left(<10^{\circ}\right)$; however, thinning of the reservoir's flow units to the southeast is also a contributing factor. This figure was created using TerraStation and was extensively reformatted outside of the TerraStation environment. 


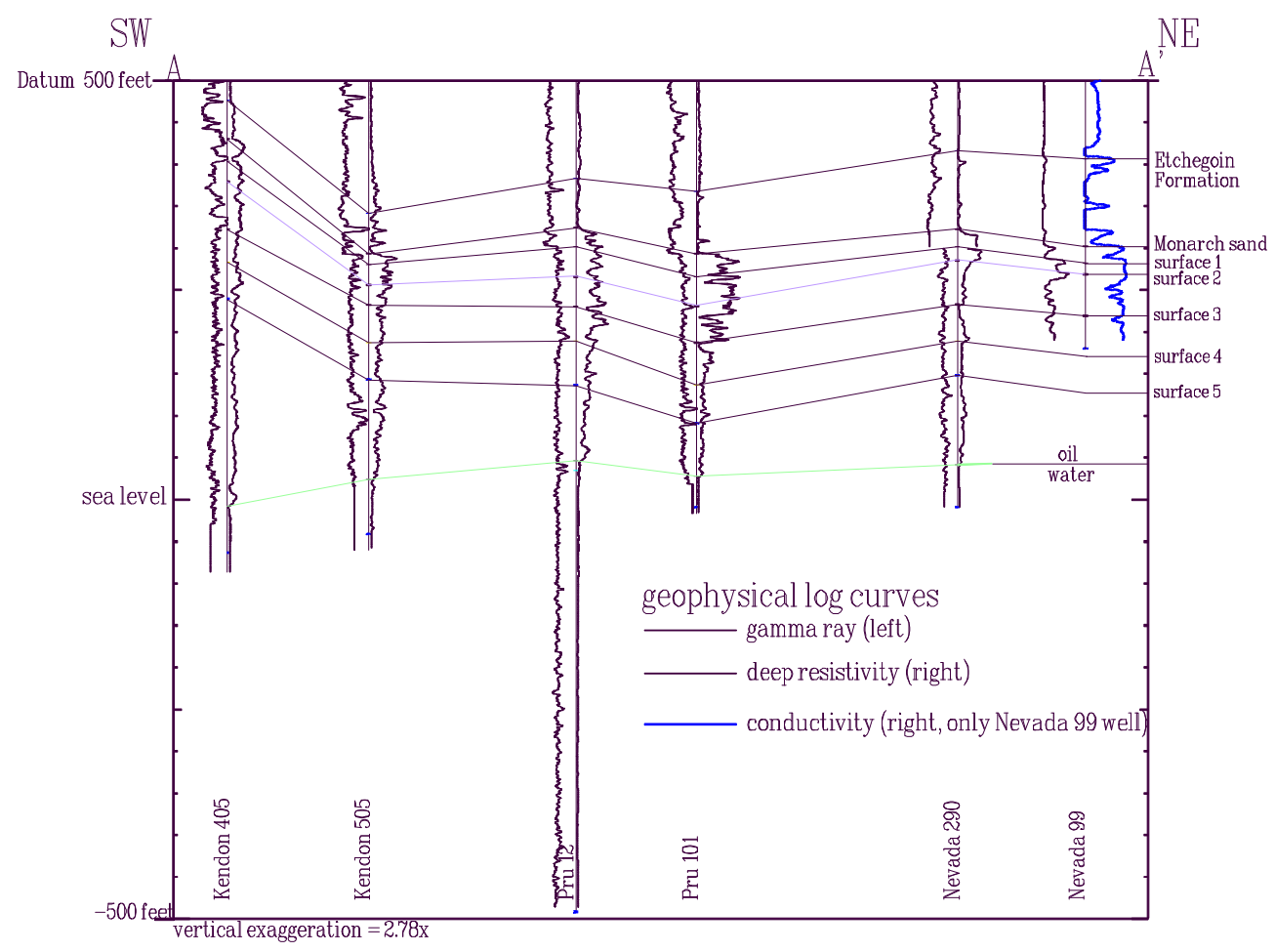

Figure 3.7. Structural cross section A-A' showing the low-amplitude syncline. This figure was created using TerraStation and was extensively reformatted outside of the TerraStation environment. 


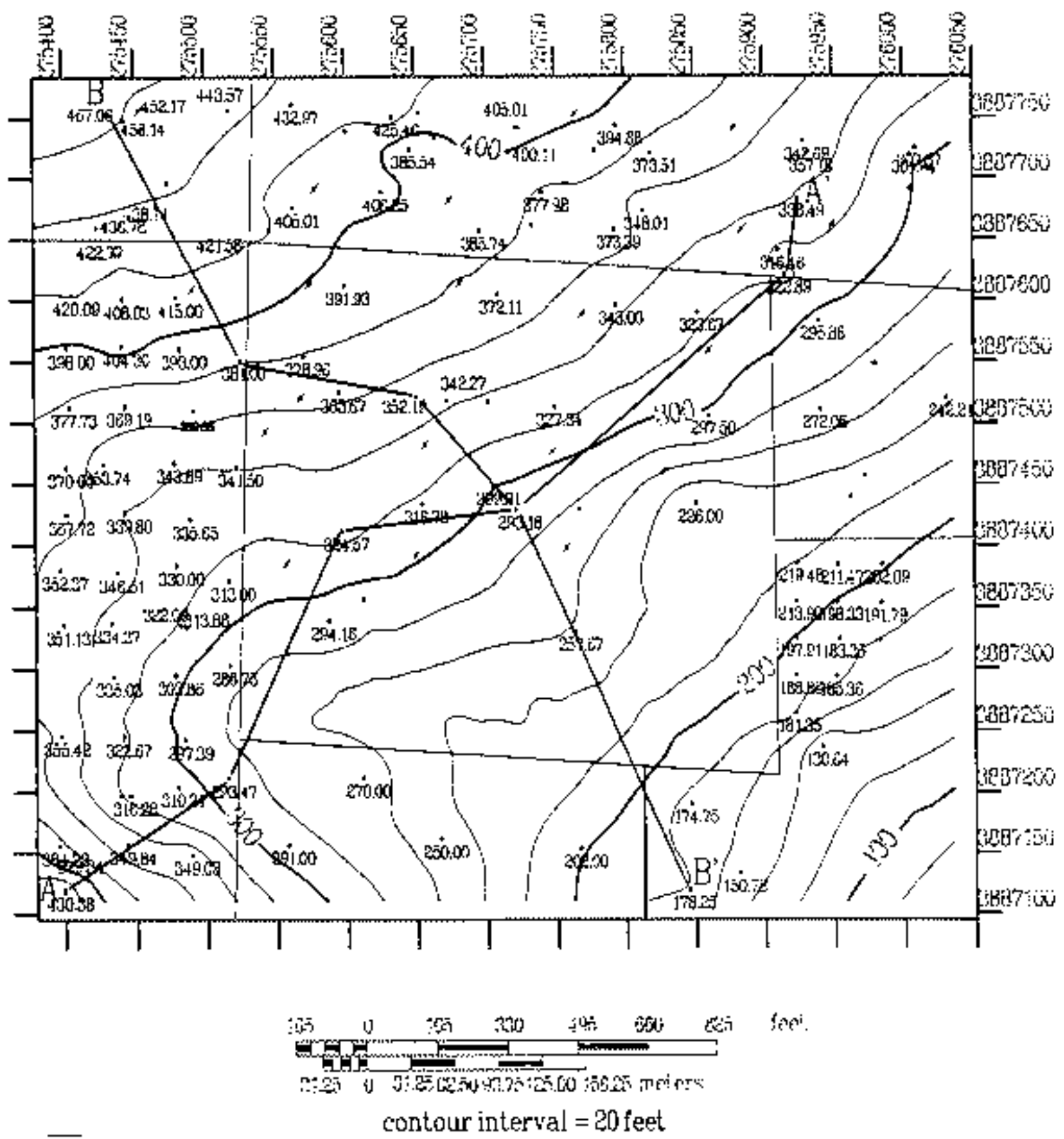

Figure 3.8. Structure-contour map of the Monarch sand. The Monarch is folded into a low+amplitude syncline that plunges southeast. Coordinate system is in UTMs, tone 11 . North is to the top of the figure. This figure was created tusing TerraStation and was extensively reformatted outside of the TerraStation ervirommekt. 


\section{Chapter 4}

\section{Reservoir Simulation}

\section{Introduction}

The primary objective of the reservoir simulation activity was to determine optimum operating conditions for the economic exploitation of the lease. The important parameters that were considered in this optimization process were:

- The type of process to be employed (cyclic, flood, etc.)

- Injection-production patterns

- Completion strategies

- Rates of injection

The idea was also to study the sensitivity of uncertain reservoir characteristics on production performance.

The two-dimensional simulations were used to examine the effectiveness of three different processes: (1) the cyclic process, (2) the steamflood and (3) the cyclic steamflood, wherein, the producers were cycled every so often during a steam flood. In addition, simulations were performed to study the effects of the reservoir dip, the thickness of the bottom-water zone. Updip and downdip injection strategies were investigated and three different injection and production well-completion plans were studied. The above-mentioned two-dimensional studies were conducted using a homogeneous model. The geologic investigations showed thick oil bearing zones separated by thin, lower permeability surfaces. Hence, an eleven-layer, two-dimensional model was used to study the sensitivity of parameters such as permeability and thickness of the surfaces. Simulation results using the layered model were compared with the results using a homogeneous analog of the layered model.

All the simulations were conducted using STARS, a thermal simulator developed by Computer Modeling Group (CMG), Inc.

\section{Two-dimensional Simulations}

\section{Processes}

The two-dimensional simulations were performed on system $1200 \mathrm{ft}$ x $10 \mathrm{ft}$ x $300 \mathrm{ft}$ in size. The grid blocks were 80 feet long, $10 \mathrm{ft}$ wide and 50 feet in thickness. There were a total of eight wells. In flooding processes half of them were injectors and the other half were producers, while in the cyclic processes all the wells operated on definite cycles.

Three different processes were investigated:

- Cyclic steam stimulation in which two weeks of injection was followed by a week of soak period and a production duration of 20 weeks. 
- Steam flood, which involved continuous steam injection in the injectors and production in the producers.

- Cyclic steam flood, which was a combination of cyclic steam stimulation and steam flooding processes. In this process, during a steam flood, the producers were steam stimulated every two years.

The cumulative oil production for the three processes is compared in Figure 4.1. The performances of the steam flood and the cyclic-flood processes are identical and appear superior to the cyclic process. Most of the oil in the flooding processes is recovered in about two years, while the duration of the cyclic steam process was 10 years to reach ultimate recovery. The flood processes were better than the cyclic process due to better reservoir sweep.

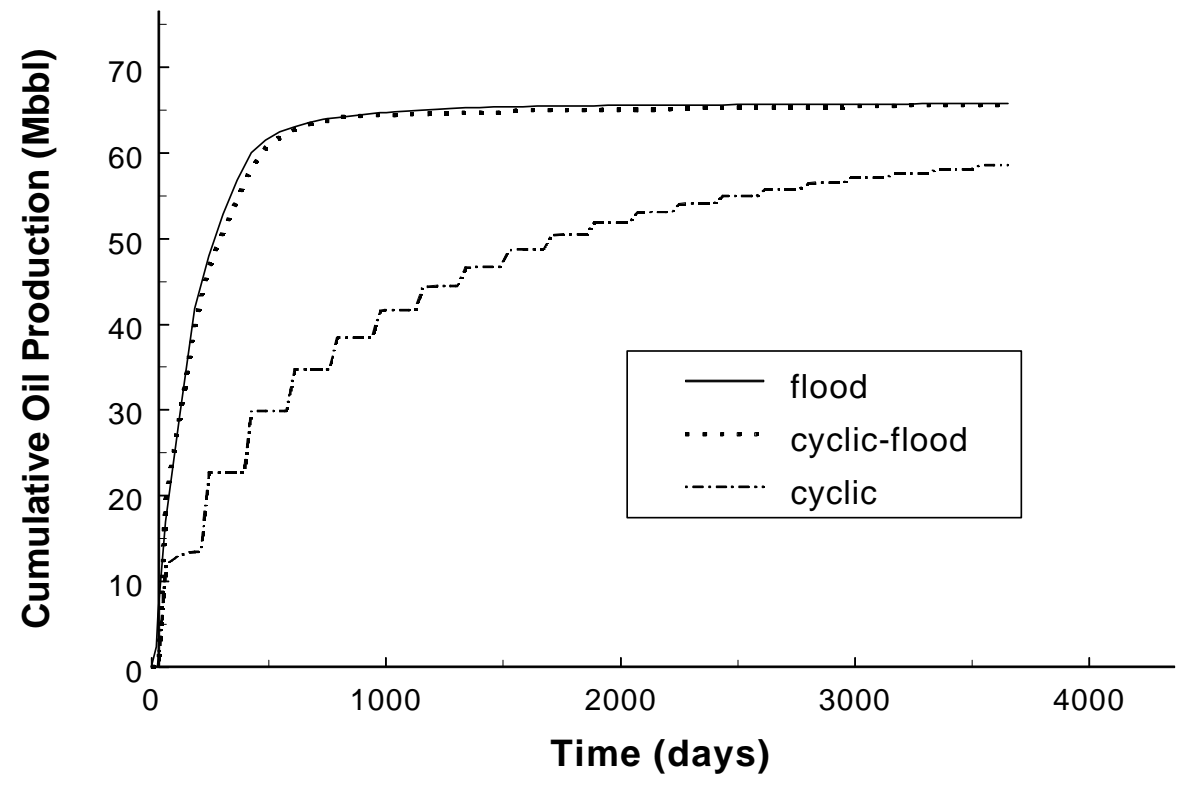

Figure 4.1: Comparison of cumulative oil production for the three processes using two dimensional simulations

\section{Dip and Bottomwater Study}

Updip injection was determined to be better for faster oil production. The reservoir dip also contributed to faster production. However, there was not significant difference in ultimate recovery when dip increased. Of the completion practices investigated, the practice of injecting steam into bottom third of the reservoir and producing oil over the entire pay interval was found most effective. A bottom water zone $50 \mathrm{ft}$ thick decreased 
oil recovery significantly. For this case, it was found that completing the injector and the producer 50 to $100 \mathrm{ft}$ above the oil water contact improved oil recovery and steam oil ratios. Details of these investigations with the homogeneous two-dimensional model are given elsewhere (Huang, 1997).

\section{Effect of Lower Permeability Surfaces}

Stratigraphic reservoir characterization revealed that the reservoir between the top of the Monarch Sand to the oil-water contact consisted of six high-permeability oil-bearing zones separated in most instances by thin zones of relatively lower permeability. The effect of the presence of these surfaces on oil production was examined by inserting five lower-permeability, layers between the oil bearing zones of the previous two-dimensional model. The permeability of the oil-bearing zones was modeled as $3000 \mathrm{md}$, while the permeabilities of the lower permeability layers was varied from 10 to $1000 \mathrm{md}$. The thicknesses of these layers were varied from $0.5-2 \mathrm{ft}$.

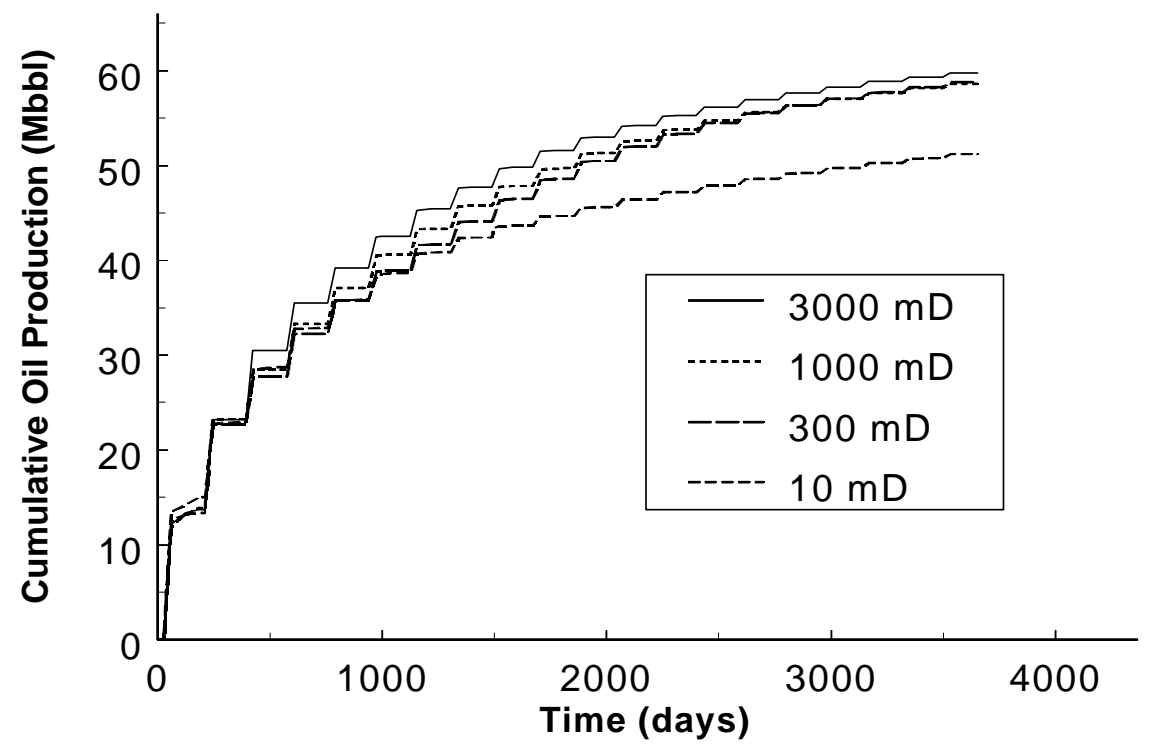

Figure 4.2: Effect of the permeability of lower permeability surfaces on oil production; cyclic process (2-D simulations)

The effect of permeability of the "barriers" on the cyclic process is shown in Figure 4.2. In this simulation, the "barrier" thickness was uniform at $2 \mathrm{ft}$. It can be seen from the figure that production is not very sensitive to the "barrier" permeability unless the surface permeability was as low as $10 \mathrm{md}$. For the flood process, the presence of a lower permeability "barrier" had a much larger impact (Figure 4.3). The surface thickness had little impact on production when the permeability was 300 md (Figure 4.4). However, 


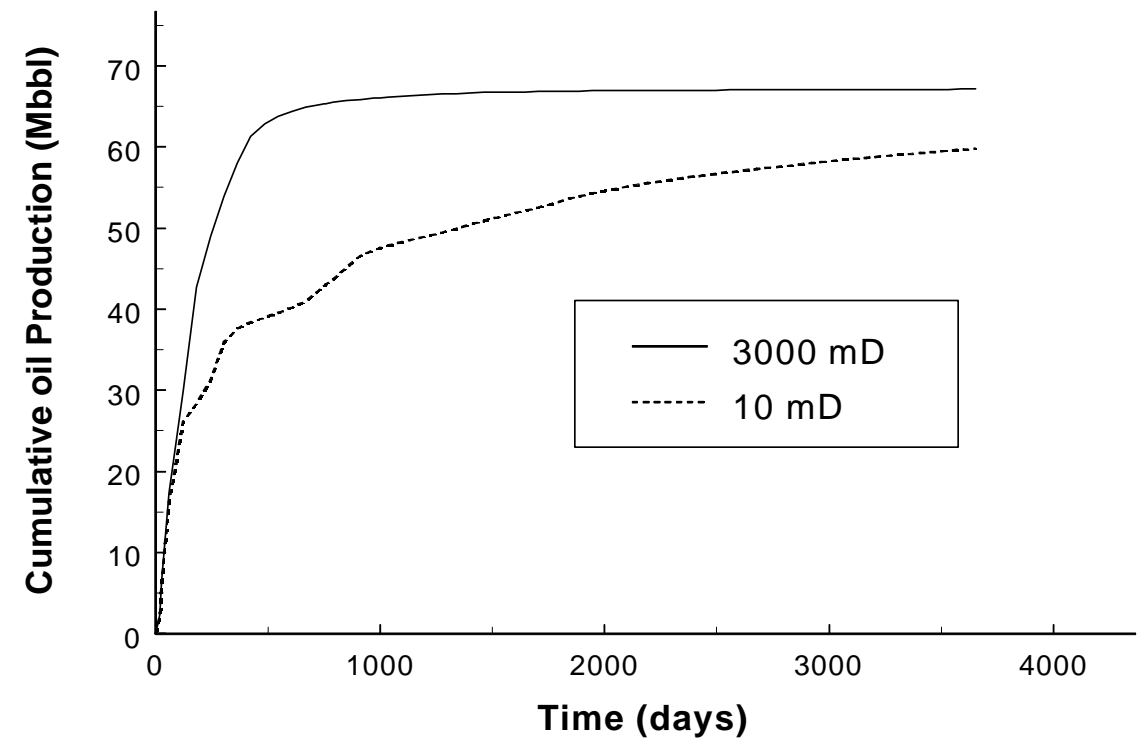

Figure 4.3: Effect of the permeability of lower permeability "barriers" on oil production; steam-flood process (2-D simulations)

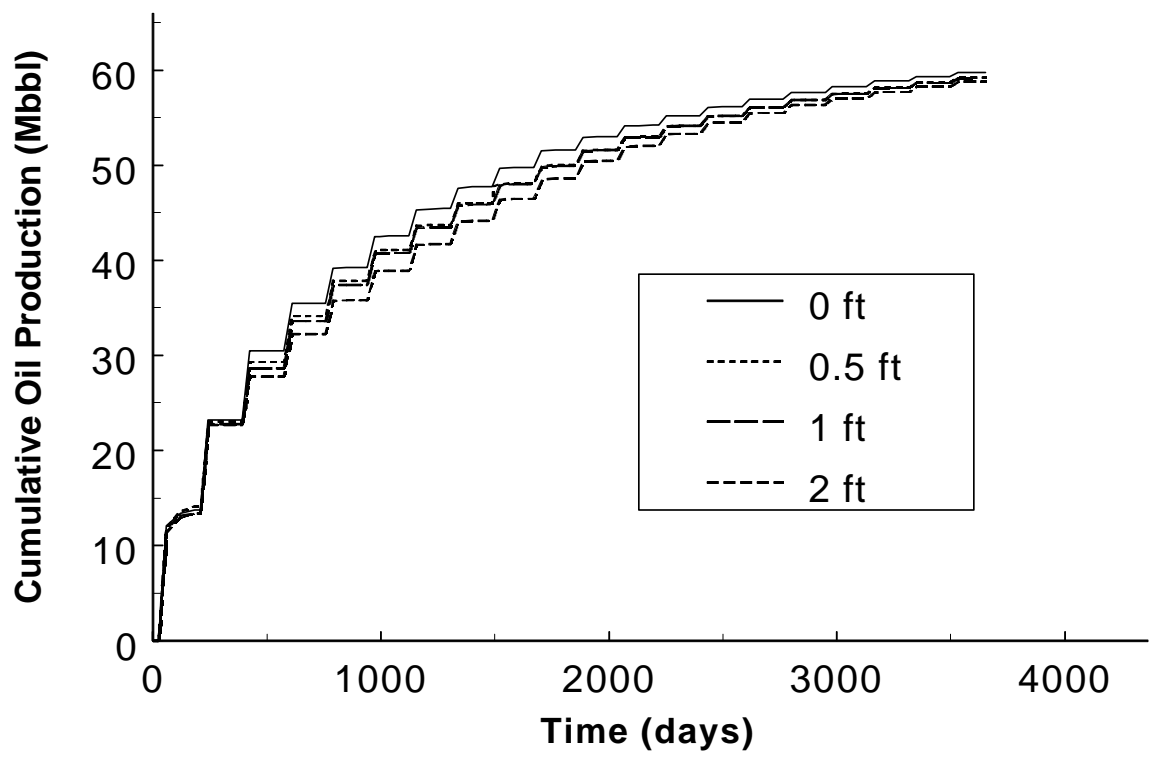

Figure 4.4: Effect of the thickness of lower permeability "barriers" on oil production; permeability of all the surfaces was $300 \mathrm{mD}$ (2-D simulations) 


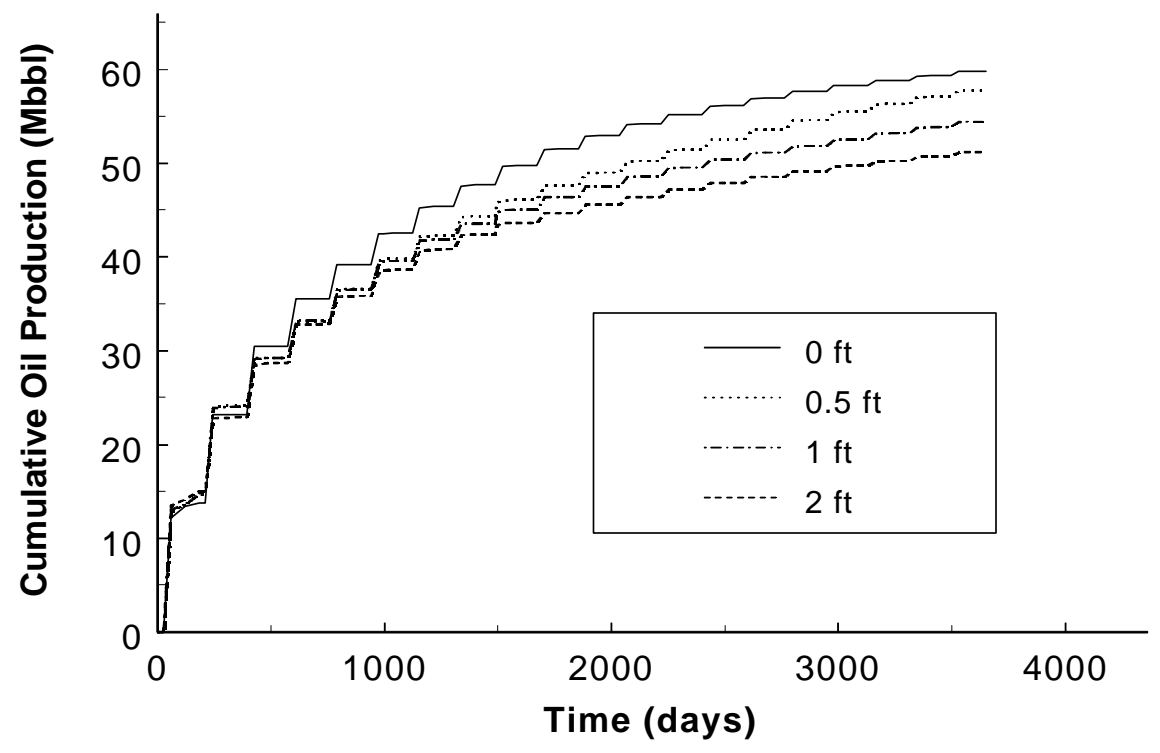

Figure 4.5: Effect of the thickness of lower permeability "barriers" on oil production; permeability of all the "barriers" is $10 \mathrm{mD}$ (2-D simulations)

when the permeability was reduced to $10 \mathrm{md}$, thickness did have considerable effect (Figure 4.5). Surface properties affected production because the surfaces inhibited vertical migration and thus vertical reservoir sweep.

A homogeneous analog of the multi-layer system was constructed. The heterogeneous system had five surfaces with permeabilities of $10 \mathrm{md}$ and each with a thickness of $2 \mathrm{ft}$. The production performance of the true heterogeneous system was compared to the homogeneous analog. It was observed that for the steamflood, there was a significant difference between the heterogeneous and its homogeneous analog, with the analog overpredicting recovery (Figure 4.6). For the cyclic process, where the vertical and lateral connectivity in the reservoir were of lesser significance than for the steam flood process, the difference was minimal (Figure 4.7). 


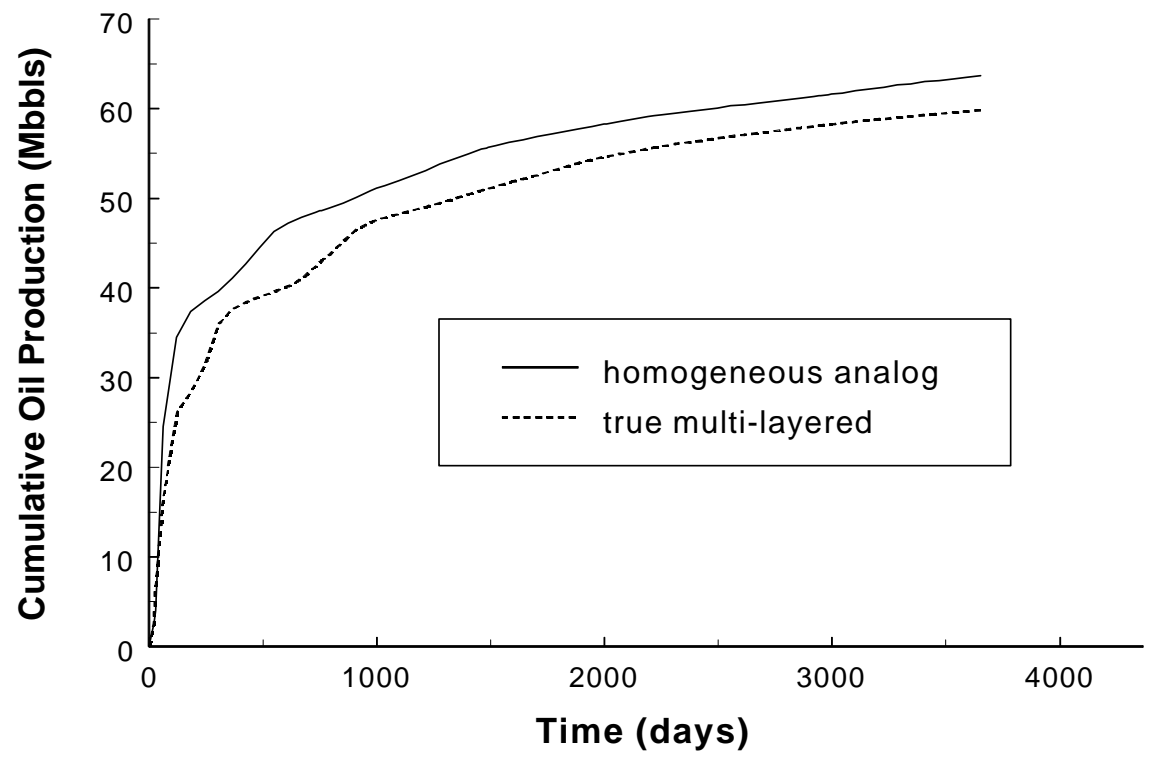

Figure 4.6: Comparison of cumulative oil production for the heterogeneous (layered) reservoir and its homogeneous analog (steam-flood process, 2-D simulations)

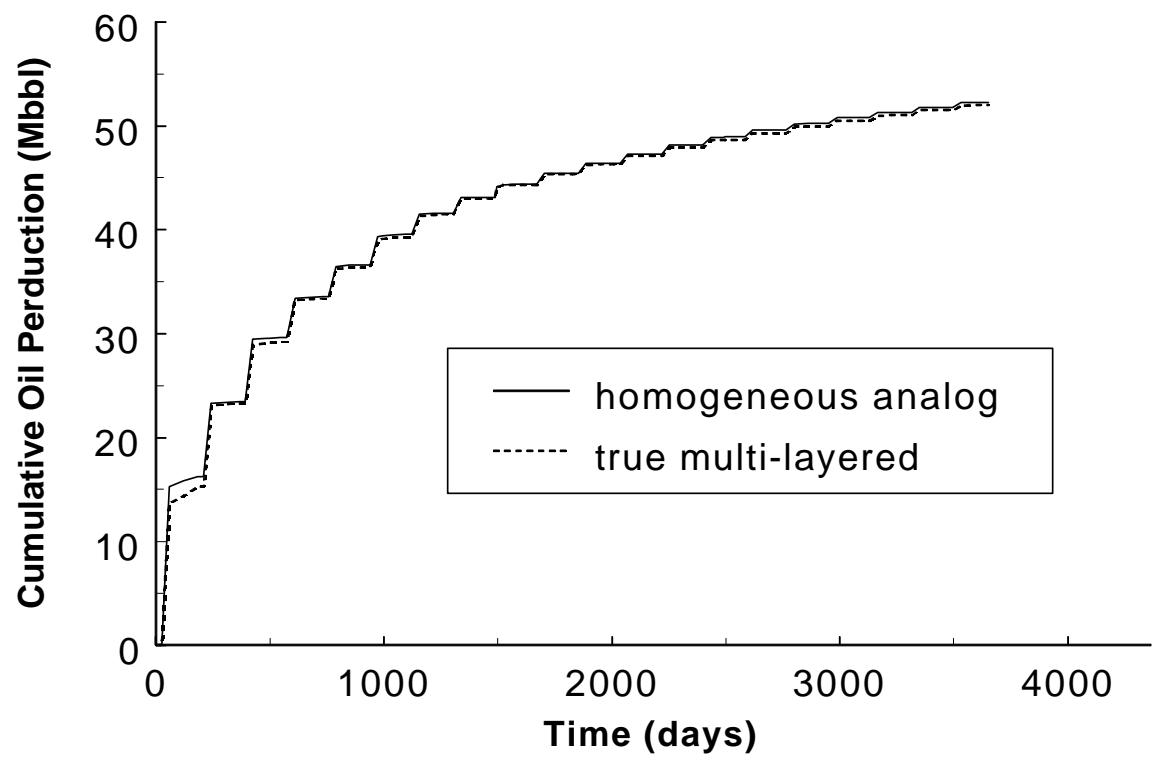

Figure 4.7: Comparison of cumulative oil production for the heterogeneous (layered) reservoir and its homogeneous analog (cyclic process, 2-D simulations) 


\section{Chapter 5}

\section{Activities at the Pru Fee Demonstration Site}

\section{Introduction}

The Pru property had been operated on and off for over 70 years prior to being shut-in in 1987. As a consequence there were many old wells and support facilities in various states of disrepair at the site. In preparation for the cyclic injection and production baseline tests, the site was resurveyed, an existing PLC panel was upgraded with new dynamic surveillance software, many of the flowlines were replaced and the production header was repaired and modified. In addition, a nearby idle freshwater knockout (FWKO) was converted to the Pru wet lact; the old Pru wet lact was converted to a well tester. This work at the site was carried out under the supervision of Robert Swain (AWE).

Idle wells on the shut-in Pru demonstration site were inspected, repaired and equipped as injection/production wells to be used in the baseline testing. In addition, a new production well, Pru 101, and a temperature observation well, TO-1, near the center of the demonstration site were planned, permitted and drilled. The wells were completed and equipped in late September, 1995. A core was removed from the producer, Pru 101, with over $80 \%$ recovery.

By the end of January 1996, all major work for the initial baseline testing on the Pru property was successfully implemented, except for the CVCS installation and gathering line upgrade. These two actions are being deferred pending evaluation of the test results and continuation of the project into the demonstration phase.

The first phase of baseline cyclic steaming, begun in November 1995, was continued into early 1996. During the first round, 70,000 barrels of steam was injected into 9 wells near the center of the Pru Fee property. Production peaked at about 90 bbls/day shortly after the close of the first round, but within a period of weeks had dropped back to about 70 bbls/day. Production was dominantly from the new Pru 101 well. The lower than expected flow rates from the refurbished older wells is attributed to completion problems that will be investigated in subsequent steam cycles. Two of the older wells came back cold immediately after steaming indicating a problem with either steam allocation among the several wells in the text or loss of steam to upper stratigraphic intervals.

The initial steam cycle demonstrated the need to better monitor both the flow of steam to individual wells and the penetration of steam into the reservoir at each well. The second round of steaming, part of the first scheduled phase of baseline testing, was begun in March 1996 under closer monitoring. This involved injecting one well at a time and surveying the formation intervals penetrated using radioactive tracers.

Cyclic Steaming Baseline Tests 
One of the main objectives of Budget Period 1 was to return the Pru Fee property to economic production and establish a baseline productivity with cyclic steaming. By the end of June 1996, all Pru producers except well 101 had been cyclic steamed two times. Each steam cycle was approximately 10,000 barrels of steam (BS) per well. No mechanical problems were found in the existing old wellbores.

After the first round of steam cycles it was readily apparent that the new Pru 101 well was producing much better than the old existing Pru wells. In fact two of the old producers had no response at all to the first steam cycle. There were several possible explanations for the difference in performance, including (1) error in steam measurement/allocation, (2) misplacement of steam in the reservoir and (3) formation damage in the older wells.

In each of the second steam cycles, only one well at a time was steamed using a single dedicated steam generator to make sure that the measured volume of steam was accurate. Injection tracer surveys also were run in each well during the cycle to determine the vertical profile of steam entry into the reservoir. The surveys indicated some variability of vertical profiles from well to well. However, none of the profiles appeared to be particularly unfavorable from the standpoint of heat distribution. There were no obvious small thief zones taking all the steam, leaving the rest of the interval unheated. Attached is a typical vertical profile (Figure 5.1) that indicates all of the steam is being confined to the Monarch reservoir, with most of the heat distributed above the tubing tail, as expected.

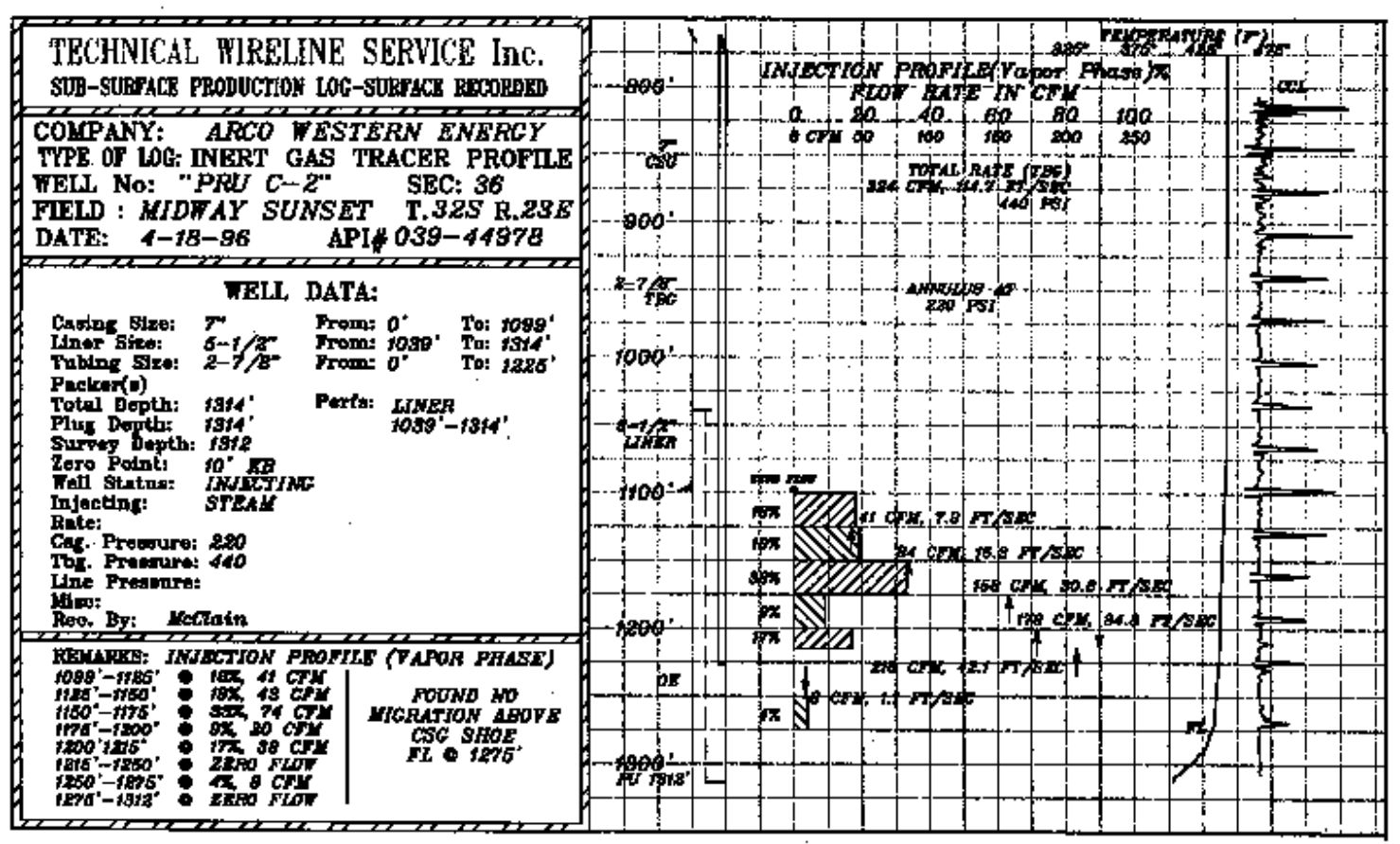

Figure 5.1: Steam injection tracer survey report for the Pru C-2 well. 
Temperature Observation Well: Temperature logs were run in the temperature observation well TO-1 to determine the heat distribution out in the reservoir away from the producers. No temperature changes were noted in the T.O. well until Pru 101 (the closest producer to TO-1) was cyclic steamed, indicating that the injected steam is heating only a limited area around each producer.

As shown on the attached graph of temperature logs over time (Figure 5.2), the only heating observed in the Monarch reservoir appears at the top of the reservoir. This implies that although the vertical heat distribution is favorable at the producers, the heat quickly migrates to the top of the reservoir, leaving most of the oil unheated. This may be due to the small partially depleted interval we observed at the top of the Monarch in the whole core and open hole logs taken from Pru 101. Even a small gas saturation in the reservoir would likely provide a "path of least resistance" for preferential flow of steam because of more favorable relative permeability as compared to the heavy oil saturated sand.

Another significant temperature increase was noted in the TO- 1 well in the Tulare Formation, approximately 500 feet from surface. This indicates that part of the heat required to mobilize oil in the Monarch reservoir is actually leaking up into the Tulare reservoir. Currently, it is suspect that this is due to an old wellbore which was not adequately abandoned several years ago. The well has since been re-abandoned, which should solve this problem. 


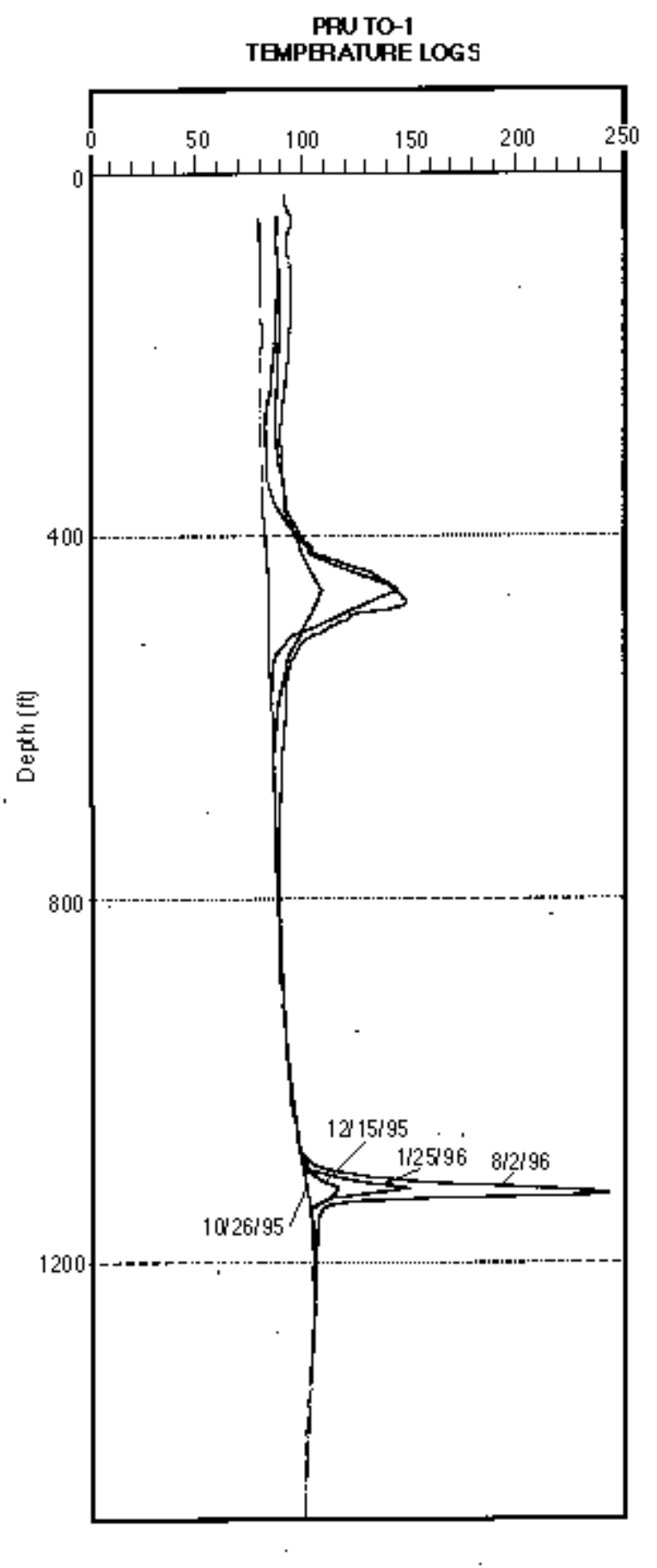

Figure 5-2: Temperature observation well 1 near the center of the Pru Fee property with recordings during the period of first-cycle steam injection showing steam migration upward into in the Tulare Formation and the upper, depleted zone of the Monarch Sand reservoir. 
Production: Total Pru Fee production following the first steam cycle was about 70 BOPD and 300 BWPD, as shown on the attached lease production plot (Figure 5.3). Due to the concerns about steam placement and measurement, the second round of steam cycles were started before production had stabilized from the first cycle. The drop in production during the second cycle is primarily due to producers being taken off line to inject the second steam cycle.

The total lease production resulting from the first steam cycle was lower than expected. As mentioned previously this is due to poor performance in the old existing wells. As seen in the attached bubble map (Figure 5.4), post steam oil rates in the older wells were less than 10 BOPD, as compared to the post steam oil rate in new Pru 101 well of 30 BOPD.

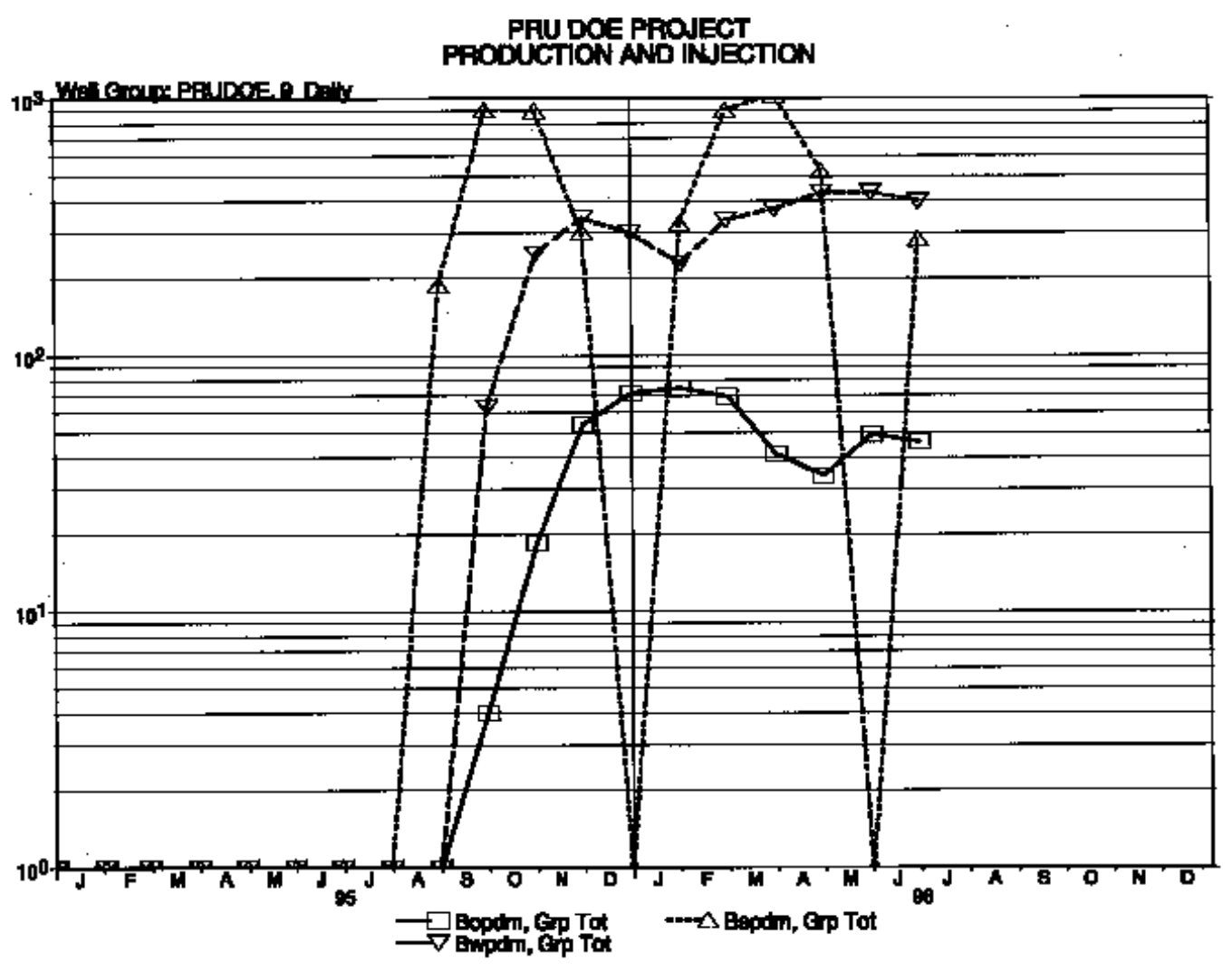

Figure 5.3: Plot of steam injection and oil production during the first cycle steam injection of the cyclic baseline test. Total for all wells in test is shown.

However, early production results following the second steam cycle are encouraging. Some wells such as producer D-1 shown in the attached production graph (Figure 5.5), are responding better to the second steam cycle. Time will tell whether this trend will continue. If it does, this may indicate that although the old wells may have a high near wellbore skin as compared to a new well, they may still have the potential to be economic producers as the reservoir heats up with continued injection. 


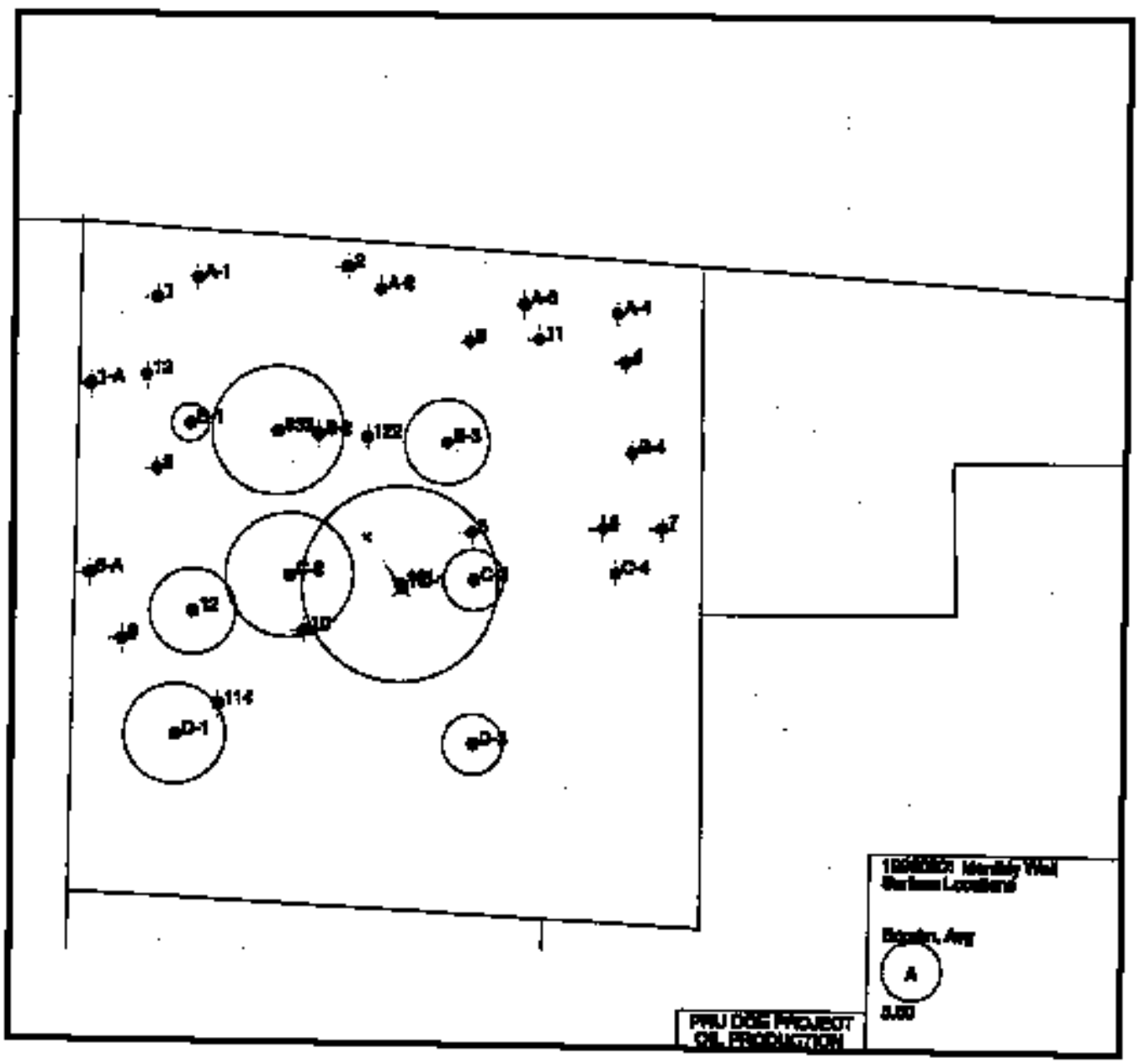

Figure 5.4: Bubble map of the Pru Fee property showing relative rates of oil production for the operating wells during the first cycle baseline test. Wells with no bubbles were not included in the test.

\section{Conclusion}

After several years of being shut-in, the existing producers on the Pru lease are in reasonable mechanical condition and therefore can be utilized as viable producers in whatever development plan is determined optimum. Production response to cyclic steam is very encouraging in the new producer, however productivity in the old producers appears to be limited in comparison.

Effectively heating the entire reservoir will be the key challenge in the economically developing the Pru lease. 


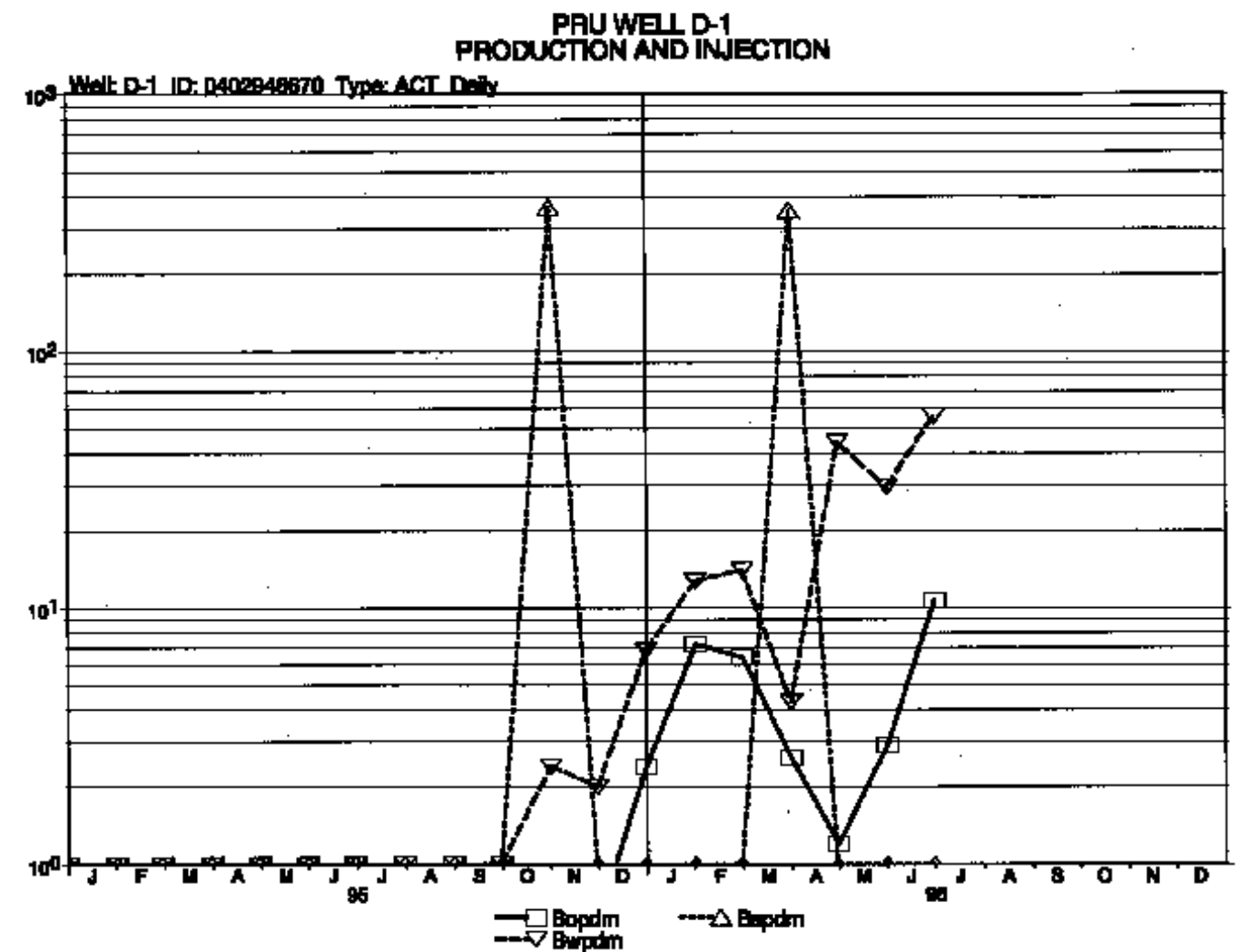

Figure 5.5: Plot of steam injection and oil production for the D-1 well during the first and second cycles. Note the increase in production rates after the second cycle. 


\section{Chapter 6}

\section{Technology Transfer}

At the 1996 annual convention of the American Association of Petroleum Geologists (AAPG) in San Diego, California, May 19-22, the project team presented an invited paper in the session Application of New Technologies to Enhance Oil Recovery. The paper entitled "Integrated, multidisciplinary reservoir characterization, modeling and engineering leading to enhanced oil recovery from the Midway-Sunset field, California" summarized the purpose of the project and the technical results to date.

The PC workstation has been purchased and is being prepared with data files and text related to the project. The public-access workstation will be placed in the Bakersfield office of the California Division of Oil, Gas and Geothermal Resources in December 1996. All project data can be examined and downloaded from this site. 


\section{References Cited}

Callaway, D. C., 1962, Distribution of Upper Miocene sands and their relation to production in the North Midway area, Midway Sunset Field, California, Selected Papers: San Joaquin Geological Society 1, p. 47-55.

Foss, C. D., and Blaisdell, R., 1968, Stratigraphy of the west side southern San Joaquin Valley, in Guidebook to Geology and Oil Fields of the West Side Southern San Joaquin Valley: American Association of Petroleum Geologists, Society of Economic Geophysicists, and Society of Economic Paleontologists and Mineralogists, Pacific Sections, Annual Field Trip, p. 33-43.

Hall, B. R., and Link, M. H., 1990, Reservoir description of a Miocene turbidite sandstone, Midway-Sunset Field, California, in Barwis, J. H., McPherson, J. G., and Studlick, J. R. J., eds., Sandstone Petroleum Reservoirs: Springer-Verlag, New York, p. 509-533.

Nemec, W., 1990, Aspects of Sediment Movement of Steep Delta Slopes, in Collella, A., and Prior, D. B. (Eds), Coarse-Grained Deltas, International Assoc. Sedimentologists Special Publication Number 10, pp 29-73.

Pennel, D. A. and Horton, R. A., 1994, Cyclic-Steam-Induced Diagenesis in Potter Sand, Midway-Sunset Field, California, in Open House Display of Potter and Spellacy Sands, California Well Sample Repository, California State University Bakersfield, Special Publication No. 4, pp. 13-17.

Schamel, S., C. Forster, M. Deo, R. Swain, M. Simmons, D. Sprinkel and R. Adams, 1996, Integrated, multidisciplinary reservoir characterization, modeling and engineering leading to enhanced oil recovery from the Midway-Sunset field, California. Presented at 1996 annual AAPG convention, May 19-22, 1996, San Diego, California.

Slider, H. C. 1983, Worldwide Practical Petroleum Reservoir Engineering Methods, PennWell Books, Tulsa, OK, p. 691.

Webb, M. G., 1978, Monarch sandstone: reservoir description in support of a steam flood, Section 26C, Midway Sunset Field, California. Journal of Canadian Petroleum Technology, October-December 1978, pp. 31-40 